\title{
A COMPLETE AND UPDATED REVIEW ON VARIOUS TYPES OF DRUG DELIVERY SYSTEMS
}

\author{
RAJEEV GARG ${ }^{1}$, SHARANPREET KAUR ${ }^{1}$, RITIKA ${ }^{1}$, SHEHNAZ KHATOON ${ }^{1}$, NAINA ${ }^{1}$, HITESH VERMA ${ }^{1,2}$
}

${ }^{1}$ Amar Shaheed Baba Ajit Singh Jujhar Singh Memorial College of Pharmacy, Bela, Rupnagar, Punjab, India 140111, ${ }^{2}$ Overseas R\&D Centre, Overseas Healthcare Pvt. Ltd., Phillaur, Punjab, India

Email: sharankashyap1@gmail.com

Received: 18 Mar 2020, Revised and Accepted: 24 Apr 2020

\section{ABSTRACT}

The World of medicine has gained considerable interest in the research area all over the World. Scientists constantly work on the three parameters 'Quality, Safety, Efficacy' of a pharmaceutical ingredient. Refine these parameters; they are continually developing different dosage forms. These unique types of dosage forms help to provide improved bioavailability and efficacy of a pharmaceutical ingredient. The role of dosage form is to improve the availability of the medicine to treat the symptoms and disease. This article focus on the different types of dosage forms, their advantages and some important facts related to that dosage forms.

Keywords: Different types of tablets, Vaccines, Microsponges, Suppositories, Capsules, Ointments, Gels, Biphasic dosage form, Targeted drug delivery systems, Osmotic drug delivery systems, Controlled drug delivery systems

(C) 2020 The Authors. Published by Innovare Academic Sciences Pvt Ltd. This is an open access article under the CC BY license (http://creativecommons.org/licenses/by/4.0/) DOI: http://dx.doi.org/10.22159/ijap.2020v12i4.37508. Journal homepage: https://innovareacademics.in/journals/index.php/ijap

\section{INTRODUCTION}

The world of medicine and medical science deals with the prevention, cure and treatment of any ailment which alters the functions of the human body. The word 'Medicine' is derived from the Latin word 'Medicus' which referred to 'a Physician'. Medicine is an agent or a substance which is taken by a person by any route to treat the abnormal functions of the body.

China, Babylon, Egypt and India introduced the medical science to the world. Indians contributed to the different type of treatments, diagnosis and medical ethics in the world of medical science. The first medical school was opened in Southern Italy in the $9^{\text {th }}$ century. Then till the $20^{\text {th }}$ century, many Universities were founded in the countries like Italy, France and England. This field progressed very rapidly after this century.

From 5000 y, Indians used Ayurvedic system of medicine and medical sciences. Plants, soil and clay were used to treat the illness. Medicine was called as 'Aushadhi' which can be plant part, soil or mixtures of some liquids which cure the disease or any infection. Ayurveda also tells about different dosage forms which are prepared by Vaidya (a physician) by applying some scientific knowledge. Then Vaidya mixed the ingredients derived from various sources by grinding, percolating or using other methods, prepared a dosage form which can be easily taken by patients.

Some dosage forms in the form of liquids like Kasaya, Arka, Sneha, Hima and Mantha; semi solid dosage forms like Kalka, Avaleha, Lepa, Malahara and Upanaha; solid dosage forms like Churna, Khanda Vati Lavana and Guggulu were formulated according to Ayurveda. In today's World these systems are revolutionized to different new dosage forms from macro systems (tablets, capsules) to micro systems (microemulsion, microparticles) and then to nano systems (liposomes, nanogels) [1]. Different types of drug delivery systems was used as search criterion to write this review. Literature survey was conducted over a number of years 1980-2020 to update and comprehensively review. The sources were papers from journals that are recognized world-wide. The keywords used as filters were-aerosols, aptamers, antisense therapeutics, osmotic systems, $\mathrm{pH}$-activated systems, micro and nano drug delivery systems.

Further more detailed form of these modern dosage forms including their general introduction, positive expressions is explained.

\section{Tablets}

Tablets are prepared by compressing the active pharmaceutical ingredients with or without additives. These are intended to be used as unit dosage forms. Tablets can be round, convex, rectangular, oval etc. having different sizes depending on the route of administration. Excipients such as diluents, binders, glidants, lubricants, disintegrants, sweeteners, flavours and granulating agents are used to formulate tablets. When the active ingredients are intended to protect from any type of environment in vivo/in vitro coating is done on the surface. The tablets are the most stable system than any other dosage forms. The release of active ingredients from the tablets can be varied by using different type of coatings and polymers [2, 3].

\section{Compressed tablets}

Compressed tablets are uncoated tablets made by compressing the drug and excipients as a single layer or multi-layer tablets. These are made by direct compression technique. Since no coating is applied on these tablets, the release of the drug will be immediately $[2,3]$.

\section{Sugar coated tablets}

When compressed tablets are coated with a layer of sugar is called as sugar coated tablets. The purpose of the coating is to mask the taste of bitter drug. By varying the thickness of the layer on can also control the release of drug from the dosage form. Sugar coated tablets have some features like stability of drugs and ease of administration when compared with film coated tablets. These tablets have a graceful look and act as a barrier for environmental changes such as oxidation and hydrolysis. The use of sugar coating is limited these days due to its size and weight [2-4].

\section{Film coated tablets}

When compressed tablets are coated by using a thin layer of polymers like cellulose derivatives and control the release of drug from the tablet. It also has an elegant appearance like sugar coated tablets. It is more stable than sugar coated film and is less bulky and manufacturing time is less. The coating can be designed according to the environment in which the drug is to be released $[5,6]$.

\section{Enteric coated tablets}

These types of tablets are coated with polymers like hydroxyl propyl methyl cellulose (HPMC), cellulose acetate phthalate, Eudragit L-100, Eudragit S-100 etc. These polymers protect the tablet from gastric environment and allow the release of the drug in the intestine. Drugs 
that are prone to gastric acid are coated with enteric coated polymers. Enteric coated polymers also delay the release of the drug $[2,7]$.

\section{Mouth dissolving tablets}

These are uncoated tablets that release the drug in the mouth when placed. These tablets disintegrate rapidly to release the drug in the mouth cavity before swallowing. It disintegrates into small granules and forms gel like structure from which the drug is released. The disintegration time is from seconds to some minutes $[2,8]$.

\section{Chewable tablets}

These are intended to release the drug in the mouth or in the buccal cavity by chewing the tablets. These are used for the drugs that have large dose and size. Chewable tablets are useful for the children and for those who have difficulty in swallowing. To mask the taste of drugs, sweeteners and flavours are added. This also improves the patient compliance $[2,9]$.

\section{Tablet triturates}

When active ingredients are mixed with powdered sucrose or lactose and then moistened, moulded into different shapes like cylindrical or compressed discs are known as tablet triturates. These are meant to be dissolved immediately. It must disintegrate rapidly therefore compression force should be used to lesser extent [2].

\section{Hypodermic tablets}

The tablets that are meant to be dissolved in distilled water to be injected as a solution by the parenteral route. These tablets are made by soluble ingredients. Sterility is the major problem with these types of tablets. Care should be taken to maintain its sterility while using these tablets [2].

\section{Gelatin coated tablets}

These types of tablets are coated with gelatin to protect it from environmental hazards like photosensitivity. Coloured gelatin is used to coat the tablet. Gelatin tablets are easy to swallow and ideal for double-blind clinical trials and the drugs that cause irritation to the mucosal lining can be formulated as gelatin coated tablets. Gelatin coating is better than sugar or film coating [2].

\section{Immediate release tablets}

As the name indicates, these tablets release the drug rapidly by disintegrating immediately and are formulated without any rate controlling coating on them. Chewable tablets, effervescent tablets, sublingual tablets and buccal tablets are mostly used immediate release tablets for administration of drugs $[2,10]$.

\section{Extended release tablets}

Controlled release, delayed release and prolonged release tablets-all are categorized under extended release tablets. These are designed to prolong the release of active ingredients in vivo at a predetermined rate. The release of the drug depends upon the physiological conditions of the body due to different type of coating and target to be treated. Sometimes, the drug releases in a pulsatile manner in order to give repeat action [11].

\section{Vaginal tablets/Inserts}

Vaginal tablets or inserts are uncoated, ovoid, pear shaped tablets employed vaginal infections. These tablets can provide local or systemic effects by dissolving slowly and releasing the drug [2].

\section{Implant tablets}

When the tablet is inserted directly into the skin (subcutaneously) with the help of surgery are known as implant tablets. They slowly release the drug over a long period of time. They have replaced the traditional system of medication. These preparations are sterilized and mostly made by the fusion method. Hormones like testosterone and contraceptives are administered by using these implants. They are made by using rate controlling polymers and additives. Formulations like pallets, resorbable microparticles, polymer implants, in-situ gel forming implants, metal or plastic implants and drug eluting stents are available in the market [2].

\section{Lozenges}

The term "Lozenge" derives from the French word "Losenge," which means a structure in the shape of a diamond with four equal sides. In pharmacy since the 20th century, lozenges and pastilles have been produced and are still under commercial production. Lozenges are solid preparations intended for mouth or pharynx dissolution. These may contain one or more drugs in a flavoured and sweetened base and are intended to treat local pain, mouth or pharynx infection and may also be used to absorb systemic drugs. We can deliver medication to the oral cavity or mucosal surface multi-directionally. Lozenges are placed in the oral cavity in a better innovative dosage form. Historically, lozenges have been used to relieve minor sore throat pain and irritation and have been widely used to provide topical anaesthetics and antibacterial treatment. Currently lozenges include the following different categories of drugs: analgesics, anaesthetics, antimicrobials, antiseptics, astringent antitussives, decongestants, demulcents, and other groups and medication combinations. These can be prepared by moulding (Pastilles) and compression tablets (Troches) depending on the type of lozenge [12-15].

\section{Advantages}

1. It can be given to patients who are having trouble swallowing.

2. Services for geriatric and pediatric use.

3. The length of the drug in the oral cavity is prolonged to achieve a specific effect.

4. Easy to plan, with minimal equipment and time required.

5. Do not require administration of the form of water intake. Systemic drug absorption by the buccal cavity may be possible.

6. Sweeteners and flavors used in the formulation that mask the taste of the drugs.

7. Like parenterals, this procedure is non-invasive.

8. While bioavailability can increase, it may decrease the dosing frequency. It can reduce the pain of the stomach.

9. It can boost the start of operation.

10. It can bypass metabolism for the first time.

11. Increased treatment of patients.

\section{Classification of lozenges}

\section{According to action site}

(a) Local impact example-Decongestants, antiseptics.

(B) Systemic Effect example-Nicotine, vitamins.

\section{According to texture and composition-}

(a) Chewy or caramel-based medicinal lozenges

(b) Compressed lozenges

(c) Soft lozenges

(d) Hard lozenges

\section{Chewy or caramel-based medicinal lozenges}

These are dosage forms in which medicinal products are incorporated in a caramel base that is chewed rather than dissolved in the mouth. The chewable lozenge, or "gummy-type" candy lozenge, is one of the most common lozenges for paediatric use. These gelatin-based pastilles were prepared by pouring the melt into moulds or uniform thickness onto a sheet $[16,17]$.

\section{Compressed lozenges}

The active ingredient may be prepared by compression when it is heat-sensitive. The process of granulation is identical to that used for any tablet compressed. These tablets differ from conventional tablets in terms of

- Organoleptic property,

- Options that do not disintegrate

- Profiles with gradual dissolution. 
The lozenge is made using heavy compression equipment to give a tablet that is harder than usual so gradually dissolving in the mouth is better for the troche. Commercially, tablet compression preparation of lozenges is less essential.

\section{Soft lozenges}

Due to the ease of extemporaneous preparation and applicability to a wide variety of drugs, soft lozenges have become popular. The bases are usually a mixture of various polyethylene glycols, acacia or similar materials. One type of these soft lozenges is the pastille, described as a soft, typically transparent lozenge variety consisting of a gelatin, glycerogelatin or acacia medication: sucrose base. Soft lozenges are similar to a drug that makes the "confection" comeback. Confections are classified as soft masses with heavy saccharinity medicinal agents [13].

\section{Hard candy lozenges}

Hard candy lozenges are mixtures of sugar and other carbohydrates in an amorphous (noncrystalline) or glassy state. They can also regards as solid syrups of sugar. The moisture content and weight of hard candy lozenge should be between, 0.5 to $1.5 \%$ and $1.5-4.5 \mathrm{~g}$ respectively. We should be dissolved or degraded gradually and evenly for 5-10 $\mathrm{min}$ and should not disintegrate. Generally the temperature requirements for their preparation are high, so heatlabile materials cannot be integrated into them. Via heating and congealing process these pastilles was prepared.

\section{Suppositories}

Suppositories are semi-solid dosage system most often placed into the rectum, vagina, or nasal cavity body to supply medications to the systemic circulation or local tissues. The drug is included into the suppository base and is prepared to either melt or dissolve in the body cavity fluid to release the drug. They are accessible in diverse weight, sizes and shapes. They use to produce local, systemic and mechanical action. These can be easily given to children, old people and unconscious patients who are unable to easily swallow the medication. These are incorporated into the body cavity to create the local effect of the drug in the base. These are inserted into the rectum to work directly and efficiently on the rectum and to facilitate bowel evacuation. These are unit dosage system. These are effective methods of administering drugs that irritate the gastrointestinal tract, cause vomiting and disrupt the acidic $\mathrm{pH}$ of the stomach juice.

\section{Types of suppositories}

\section{Rectal suppositories}

For their systemic effect, these are intended to be introduced into the rectum. These types of suppositories are usually made from Theobroma oil and are available in diverse sizes to meet the needs of infants, adults and children. Weight of rectal suppository is usually 1-2 g. They are either torpedo or cone shaped.

\section{Vaginal suppositories}

These are intended to be introduced into vaginal. Also known as pessaries, these suppositories are larger than rectal suppositories. Vaginal suppositories may be conical, rod shaped, or wedge-shaped and usually 4-8 of weight is available. Vaginal tablets and vaginal capsules that have replaced vaginal suppositories are also available nowadays.

\section{Nasal suppositories}

These are meant for nasal cavity penetration and are also known as nasal bougies. These are similar to the suppositories of urethra. These are small and cylindrical in shape and are always made with a base of glycero-gelatin. They are about $9-10 \mathrm{~cm}$ long and about $1.0 \mathrm{~g}$ in weight.

\section{Urethral suppositories}

These are meant for urethra implementation and are also referred to as urethral bougies. To allow insertion, these are small, long and cylindrical shapes at one end. Their weight ranges between 2-4 g. These suppositories are used very seldom.

\section{Ear cones}

These are intended for ear insertion and are also known as aurinaria. These are rarely used today. These suppositories are about $1 \mathrm{~g}$ in shape and weight, thin, long, and cylindrical. Usually theobroma oil is used to prepare the ear cones $[18,19]$.

\section{Pellets}

Pelletized dosage forms date back to the 1950s, when the first product was introduced to the market. In 1949, research scientists of SmithKline and French advanced tiny drug pellets which are filled into capsules. Since then, these dosage forms have gained considerable popularity because of their distinct benefits inclusive of enhancement of drug dissolution. Pellets are small, free flowing, systematically produced, spherical or semi spherical solid units, geometrically defined agglomerates of about size ranging from 0.2 $\mathrm{mm}$ to $2.0 \mathrm{~mm}$, obtained from numerous starting materials of fine powders or granules of bulk drugs and excipients using different pelletization techniques. Pellets supposed for oral use are administered in the form of hard gelatin capsules or disintegrating tablets which rapidly liberate their contents inside the stomach and gets distributed all through the gastrointestinal tract without loss of the depot impact as the sub-unit acts as self-contained depots. Pellets offer greater flexibility within the design and development of an active element into oral dosage forms like tablets, capsules and suspension with significant therapeutic benefits over single units. As subunits various kinds of particles with described less-porous surface, spherical shape, and low surface area to volume ratio are suitable for flexible and uniform drug polymer coating [20].

\section{Capsules}

The term 'Capsule' derived from Latin word Capsula [21]. The invention of the gelatin capsule is generally credited to Moths and Dublanc, two Frenchmen. Their patents, issued in March and December 1834, covered a method of producing single-piece, oliveshaped, gelatin capsules that were closed after a drop of condensed, moist gelatin solution had been filled. In 1865, the two-piece telescopic tube, invented by London's jam Murdock, was patented in England [22]. In pharmacy, capsule term has been used to define a glass ampoule and also as a name of a protective cap over the stopper of a bottle of medicine. Recently, capsules have been mainly used to identify types of solid dosage form, consisting of a container which is filled with medicinal material. Capsules are divided in two classes,' soft capsule' (one piece) and 'hard capsule' (two piece) according to the presence of glycerol or another plasticizer that make it soft and elastic [23]. Benefits of capsules such as drugs with an unpleasant smell and taste can be conveniently administered; Less supplements are needed compared to tablets; they are inexpensive; once they come into contact with water, they are slippery and quick to swallow with water; the shells are physiologically inert and digested in the GIT easily and quickly; the shells can be opacified or coloured to provide light protection [24].

\section{Ocular drug delivery system}

Ocular drug delivery systems are used for the treatment of eye infection/diseases by installing directly into the eye (topical, intraocular and periocular). Ocular preparations are sterile and free from particles and pyrogens. Eye drops, eye ointments, eye lotions etc. are the examples of ocular drug delivery systems.

Eye drops are meant to be installed into the conjunctiva sac and can be hydrophilic and/or lipophilic preparations. These are sterile preparations which are free from any particulate matter. Drugs like antiseptics, anaesthetics, mydriatics and meiotic can be incorporated into eye drops.

Eye Ointments are semi-solid aseptic preparations. They are composed of mineral oil and soft paraffin with drugs and are anhydrous primarily. Due to its semi-solid nature, it stays for prolong time in the eye and provide better bioavailability. These are available for single use also to avoid contamination.

Eye Lotions are concentrated preparations used for washing of eyes. It can be diluted with warm water. These preparations must be 
isotonic, sterile and free from grittiness. The $\mathrm{pH}$ of the solution must be equal to lachrymal fluid and should be non-irritant $[25,26]$.

\section{Aerosols}

Pharmaceutical aerosols are the systems in which propellants are used to disperse fine drug particles into it under pressure. So aerosols are defined as pressurised systems containing therapeutic ingredients which deliver the drug in mist or gaseous form upon pressing the outlet valve. Sterilization can be maintained throughout its shelf life. By using metered dose valve, potent drugs can be administered with safety and accuracy. The drugs are protected from environmental factors like oxidation, hydrolysis and light [27].

\section{Buccal drug delivery system}

Buccal drug delivery system is a system in which the drug is delivered through the buccal mucosa [28]. Buccal mucosa lines the inner area of cheeks $[29,30]$. Advantages of buccal drug delivery system such as it avoids first-pass metabolism and enzyme metabolism; as compared to sub-lingual, buccal drug delivery system have large surface area; in case of toxicity it can be easily removed and easy to administer; it plays important role in that case in which patients are unconscious and comatose [31,32].

\section{Gastro-retentive drug delivery system}

Gastro-retentive drug delivery systems can stay in the gastric area for several hours, substantially increasing drug residence and prolonging gastric retention; enhancing bioavailability, decreasing drug waste and improving solubility. Gastro retention provides better availability and local drug delivery to stomach and intestine [33]. Categories of gastroretentive drug delivery system are effervescent system, noneffervescent system, hollow microspheres/microballons and microporous compartment system [34].

These drug delivery systems offer benefits such as drug delivery in small intestine area with narrow absorption window. Floating systems are beneficial for stomach absorbed drugs e. g. antacid salt. Specific site intake from the upper part of the gastrointestinal time may lead to the development of drugs with poor bioavailability as a floating drug delivery system to maximize their absorption. Due to the long term release impact, floatability and standardized release of the drug through a multi-practice scheme preventing gastric irritation. These systems provide better therapeutic effect of short lived medicinal products [35].

\section{Nasal drug delivery system}

Nasal drug administration has been used as a different route for the systemic availability of drugs constrained to intravenous administration. This is due to the large surface area, porous endothelial membrane, high total blood flow, metabolism avoidance and ready accessibility. Upon intranasal administration, drugs are quickly removed from the nasal cavity, resulting in rapid systemic drug absorption [36, 37]. For the following reasons, nasal delivery is considered a promising technique: The nose has a large surface area accessible for drug absorption due to the penetration of the epithelial surface by multiple microvilli, the subepithelial layer is highly vascularized, the venous blood from the nose passes directly into the systemic circulation and thus avoids the loss of the drug through firstpass metabolism in the liver, allowing lower doses, quicker therapeutic bladder attainment, less side effects, high total blood flow per $\mathrm{cm}^{3}$, easily accessible porous endothelial basement membrane, and drug delivery directly to the brain via olfactory nerves [38-40]. The respiratory mucosa is the perfect area for the absorption of drugs [41].

\section{Pulmonary drug delivery system}

Drug deliveries to the respiratory tract, via inhalation, to treat the bronchial diseases are referred as pulmonary drug delivery systems. This system is very beneficial in the treatment of asthma, chronic obstructive broncho-pneumopathy. Therapeutic action is fast due to the direct administration on the site of action. These systems also bypass the first pass metabolism. Dose is less and ease of administration provides better patient compliance. Pressurized metered dose inhalers (pMDI) or dry powder inhalers (DPI) are the examples of pulmonary drug delivery systems [42].

\section{Hepatic drug delivery system}

It is the type of targeted drug delivery systems. The drug is administered via any type of novel drug delivery systems such as liposomes, niosomes, microparticles etc. When the drug reaches at the site if action i.e. liver via blood circulation, the drug is actively taken by hepatic cells and cure the hepatic diseases. The delivery systems must be made in such a way that they only release their drug on target site and should be protected from harsh environment of other organs. The drug must accumulate within the liver cells to achieve the desired therapeutic concentration. Probucol liposomes, Mannosylated superoxide dismutase (SOD), Ursodeoxycholic acid (UA) modified protein-lipid nanocomplex, Super paramagnetic iron oxide (SPIO) nanoparticles are some drugs used to treat hepatic disorders [43].

\section{Monoclonal antibodies}

Monoclonal antibodies are defined as the single clone molecules of a particular parent cell which are produced by hybridoma cells or cell line and is identical i.e. identical in structure, idiotype, affinity, and specificity for specific epitope. Monoclonal antibodies can be used alone or in conjugation with drugs, toxins, cytokines or isotopes. In the past years, the main source of the antibodies was human or animal blood but it had a basic issue i.e. it contains polyclonal antibodies meaning it can bind to several epitopes and show many type of immune reactions. It has advantages like one can get unlimited supply of single type of antibodies having specific activity to unlimited period of time $[44,45]$.

\section{Aptamers}

Aptamers are defined as oligonucleotides that are derived by the process Systematic Evolution of Ligands by Exponential Enrichment (SELEX). They are categorised as DNA or RNA aptamers having short strands of oligonucleotides and peptides aptamers having one or more peptide chains. Aptamers inhibits the activity of cancer cells and bacteria. Aptamers control the release of bio molecule therapeutics. But aptamers form weak bonds with the protein binding sites which are too weak to show its activity. They also help to activate the Polymerase Chain Reaction (PCR) enzymes which initiate the initial phases of Polymerase Chain Reaction $[46,47]$.

\section{Antisense therapeutics}

These are defined as short length single stranded DNA or RNA having base sequence complementary to particular gene or its mRNA. Antisense oligonucleotides block the activity of ribosomal machinery or activate the endogenous RNAase that break the mRNA at duplex site by inhibiting the expression of unwanted cell protein by recognizing Watson-Crick complementary base and hybridize it to the target mRNA. The example of phosphodiester oligonucleotides is phosphorothioate oligodeoxynucleotides (PS-oligonucleotides) containing a sulphur instead of oxygen in one of the non-bridging phosphate. Due to this it inhibit the rapid degradation by nucleases. These have many properties like binding affinity to the target (mRNA), cellular uptake, hydrophilic and the ability to activate RNase $\mathrm{H}$, which is required for antisense activity $[48,49]$.

\section{Sedds, Smedds, Sndds}

These systems are formed by mixing surfactants, co-surfactants, and drugs and made isotropic mixtures. When this mixture comes in contact with water it forms microemulsion with fine droplets in the biological system. These are better than other lipid formulations because of use of surfactants. The formed droplet size of selfemulsifying drug delivery system ranges between 100 to $300 \mathrm{~nm}$ [51]. Self-microemulsifying drug delivery system has particle size less than $50 \mathrm{~nm}$ and self-nanoemulsifying drug delivery system have particle size in nano range [50].

Medium chain triglycerides are used to make self-microemulsifying drug delivery system because of their better solubility and self-emulsifying properties. Only specific type of excipients can be used to prepare selfmicroemulsifying drug delivery system. Drugs that are soluble in lipidsurfactant mixture can be incorporated in self-microemulsifying drug delivery system. These are transparent in nature. 
Self-nanoemulsifying drug delivery systems are better due to patient compliance and are more stable. Self-nanoemulsifying drug delivery systems are anhydrous in nature therefore hard gelatin capsules are made to store the dosage form and for administration also [52].

\section{Vaccines}

Vaccines are the preparations made by using biological sources to fight against a particular disease when injected to human or animal by the process called vaccination. Micro-organisms that resembles the pathogen of disease are extracted and attenuated or killed by chemical processes are used to make vaccines. Vaccines can be given prior to the disease as prophylactic vaccines and/or can be given when a person catches a disease as therapeutic vaccines [53].

Attenuated vaccines are those made by decreasing the activity of virus so that it cannot cause disease itself. Examples of this type are typhoid, yellow fever, measles, mumps, BCG (for tuberculosis) and rubella $[54,55]$.

Inactivated vaccines are those made by killing the bacteria or virus and injected into the body which stimulates the immune system to create immunity against that particular system. Examples are polio vaccine, hepatitis A vaccine, rabies vaccine and some influenza vaccines [56].

Toxoid vaccines are made by using inactivated toxic substances that are responsible for the disease/infection instead of bacteria or virus. Examples are tetanus and diphtheria [57].

Subunit protein vaccines are made by using only protein part of the bacteria or micro-organism or virus instead of using whole bacteria or virus. These proteins are capable of generating immune responses. Some subunit vaccines are subunit vaccine against Hepatitis B virus, the virus-like particle (VLP) vaccine against human papillomavirus (HPV), and the hemagglutinin and neuraminidase subunits of the influenza virus [58].

\section{Colon targeting drug delivery system}

This drug delivery system is designed to treat the local infection in the lower part of the gastrointestinal tract (GIT) and minimizing the side effects of the drugs. This system enhances the concentration of the drug by protecting its absorption in upper part of the gastrointestinal tract and made it more available in the colon to treat the disease. It provides therapeutic satisfaction to the patients in terms of safety, efficacy, and patient compliance. The contents in the colon stay more than $5 \mathrm{~d}$ so complete drug absorption can be obtained but stability of the drug can be compromised [59].

\section{Gene drug delivery system}

The newly discovered drug delivery system is the treatment with genes. In this therapy, no drugs are needed to treat the disease. The infected genes are removed, modified or mutated and then again inserted in the infected cell. This leads to the fast and complete recovery of the disease. It is beneficial to treat the genetic problems, cancers and certain viral diseases. The gene delivery systems comprises the three substances such as a gene expression system that contain plasmid (that controls the function of a gene within the targeting cell), a gene (to encodes a specific therapeutic protein), and a gene delivery system (to control the delivery of the gene expression plasmid) to the target gene within the body [60].

\section{Magnetic drug delivery system}

This drug delivery systems based on the nanoparticles with iron oxide as a vehicle for delivery of drugs. Single molecule magnets are used to transfer the toxic drug to the target site without incorporating the iron oxide in that site. The main problem with this drug delivery system is the excess concentration of iron oxide which leads to adverse effects. But this method is beneficial in cancer treatment by formulating "anticancer nanomagnet" [61].

\section{Brain drug delivery system}

When the drug deliveries are designed to cross the different brain barriers are called as brain drug delivery systems. Highly lipophilic drugs can cross blood brain barriers easily and target the brain tumours and other infections in the brain. But due to the clearance of the drugs rapidly from the brain cannot maintain the therapeutic concentration of the drug. Barriers are the main problem for the delivery of the drugs to the brain. There are many micro and nano drug delivery systems that facilitate the delivery of hydrophilic and lipophilic drugs across the barriers [62].

\section{Mucoadhesive drug delivery system}

Mucoadhesion is generally defined as the adhesion between two materials, of which at least one is a mucosal surface. Mucoadhesive dosage systems may well designed to enable prolonged retention at the site of application, providing a controlled rate of drug release for better therapeutic outcome. The application of dosage forms to mucosal surfaces may be beneficial to drug molecules that are not appropriate for the oral route, such as those suffering from acid degradation or severe first-pass metabolism. Topical and local systems based on Mucoadhesive have shown increased bioavailability. Mucoadhesive drug delivery results in fast absorption and strong bioavailability due to its large surface area and high blood flow. Drug delivery across the mucosa bypasses the first-pass hepatic metabolism and prevents gastrointestinal enzymes from degrading. Thus the mechanism of delivery of mucosal drugs could be of use in delivering a growing number of high-molecular-weight responsive molecules such as peptides and oligonucleotides. Mucoadhesive drug delivery system plays an important role in controlled drug delivery system [63, 64]. Benefits of Mucoadhesive drug delivery system such as;

- Targeting drug delivery system;

- High flux of drugs in the absorbing tissue

- Good accessibility

- Painless administration

- Avoid first pass metabolism

- Low enzymatic activity

\section{Bioactive drug delivery system}

It is defined as the system in which biomolecules like protein and peptides are delivered into the body. These systems are used to protect the bioactive molecules from the harsh environment of the body. Proteins and peptides (like insulin, silk molecules), polysaccharides, lipids, minerals etc can be delivered using systems like emulsions, encapsulation and others. Edible materials can be incorporated into this type of system. McClements et al. studied the delivery of bioactive compounds by emulsion based systems. They focussed on the materials used to formulate these systems to deliver the bioactive molecules in the body $[65,66]$.

\section{Osmotic drug delivery system}

When drug release is dependent upon osmotic pressure is called osmotic drug delivery system. Osmotic pressure controls the release of the drug from the dosage form. There is a semi permeable membrane that controls the permeability of biological fluids. The substance that creates pressure to push the drug layer out of the system is called osmogent. The drug is delivered through the orifice is made by laser drilling. This type of drug delivery system is independent of other physiological factors. Drug release can be expressed as zero order release kinetics. The drug release from this type of dosage can be targeted, delayed as needed $[67,68]$.

\section{Transdermal drug delivery system}

Drug delivery through the skin is known as Transdermal drug delivery systems. The drug can be transferred through the skin via transdermal patches, inotophoresis, through microfibricated needles and electroporation.

\section{Transdermal patches}

A transdermal patch is a drug containing sticky patch which is applied on the skin and delivered the drug to the systemic circulation avoiding first pass metabolism. It is a painless system to deliver the drug to treat the problems. It improves the patient compliance. It can be easily removable in case of adverse effects and when treatment is required no longer. Controlled drug delivery can be achieved through this system of medication. Drug release can be 
achieved for several days to several months. Drug release is constant and passively therefore therapeutic concentration can be maintained. The particle size of the drug must be less than 1000 units to be incorporated into transdermal patches and the drug must have lipophilicity and hydrophilicity to some extent $[69,70]$.

\section{Inotophoresis}

It is a process of applying a few miliampere of current to the particular part of the skin for a few milliseconds by using electrodes. These electrodes remain in contact with the formulation and skin and therefore allow the passage of the drug through skin and heal the problem. The example is administration of Pilocarpine and Lidocaine (for anaesthetic purpose).

\section{Micrfibricated microneedles}

This system has a drug reservoir and needle like projections called microneedles which extend from the drug reservoir and projects onto the skin. The needle like projections acts as microneedles and transdermal patch which help to deliver the drug through the skin.

\section{Electroporation}

Drug delivery by electroporation is assisted by using high voltage electric pulses. These pulses dilate the epidermis cells and make pores in the skin. Then the drug diffuse through these pores into the skin.

\section{Microspheres}

Microspheres are small spherical particles, with diameters $1 \mu \mathrm{m}$ to $1000 \mu \mathrm{m}$. They are spherical free flowing particles consisting of proteins or synthetic polymers which are biodegradable in nature. There are two types of microspheres; microcapsules and micromatrices, which are described as-Microcapsules are those in which entrapped substance is particularly surrounded by distinct capsule wall and micromatrices in which entrapped substance is dispersed during the matrix. Microspheres are every so often referred to as microparticles. Microspheres can be manufactured from various natural and synthetic materials. Microsphere plays a vital role to improve bioavailability of conventional drugs and minimizing side effects [71].

\section{Advantages of microspheres}

- Particle size reduction for enhancing solubility of the poorly soluble drug.

- Decrease dose and toxicity.

- Better drug utilization will improve the bioavailability and reduce the incidence or intensity of adverse effects

- Provide constant and prolonged therapeutic effect.

- Provide constant drug concentration in blood thereby increasing patient compliance.

\section{Microcapsules}

Microencapsulation is the method of enclosing a substance inside a miniature known as the capsule. Microcapsule is a small sphere with a uniform wall around it. The material inside the microcapsule is referred to as the core/inner phase, whereas the wall is every so often called a shell/coating. The microcapsule size ranges from $1 \mu-7 \mathrm{~mm}$. All the three states i.e. solid, liquid and gas may also be encapsulated which may additionally have an effect on the size and shape of capsules. If the solid or crystalline material is used as the core, the resultant capsule can also be irregularly shaped. If the core fabric is liquid, simple spherical capsules containing a single droplet of encapsulate may additionally be formed [72].

\section{Advantages of microcapsule}

$\checkmark$ Microcapsule used for sustained or prolonged release.

$\checkmark \quad$ It is also used for masking taste and odour of many drugs to improve patient compliance.
Vaporization of many volatile drugs e. g. methyl salicylate and peppermint oil can be prevented by microencapsulation.

$\checkmark \quad$ It can reduce toxicity and GI irritation including ferrous sulphate and KCl.

$\checkmark \quad$ It can be used for converting liquid drugs in a free flowing powder.

\section{Microsponges}

Won developed microsponge technology in 1987 andamp; filled original patent for the same and it is assigned to polymer system. Their organization developed with versions a number of products for pharmaceutical and cosmetic use. Microsponges consist of polymeric drug delivery system porous microspheres. They are sponge like structure consisting of a myriad of interconnecting voids within a non-collapsible structure with a large porous surface and spherical in shape. Microsponges are notably stable with less side effects and having ability of modifying drug release. The microsponges are spherical in nature and having particle size ranging from $5-150 \mu \mathrm{m}$. Microsponges are the cross-linked, porous, polymeric microspheres which accumulate the flexibility to entrap a variety of active ingredients. They are in most cases used for topical and oral administration with altering release rate. The microsponges i.e. microsponge drug delivery system (MDDS) consist of size 5$150 \mu \mathrm{m}$ in diameter; with a ordinary $25 \mu \mathrm{m}$ sphere can up to 250000 pores and an interior structure of pore equal to $10 \mathrm{ft}$. in size which provides a total pore volume of $1 \mathrm{ml} / \mathrm{gm}$. This type of system exhibits large reservoir within microspongic structure, which can be loaded with the identical weight of active ingredient [73].

\section{Advantages of microsponges}

$\checkmark \quad$ Microsponges can prevent accretion of active ingredient in the epidermis and dermis.

$\checkmark$ Microsponges can reduce irritation of effective drug by maintaining their effectiveness.

$\checkmark \quad$ Microsponges drug delivery system increases residential time of a drug on skin surface or in epidermis.

$\checkmark \quad$ Microsponges has stable over range of $\mathrm{pH} 1$ to 11 , temperature up to $120^{\circ} \mathrm{C}$.

$\checkmark \quad$ Microsponges well-matched with most vehicles and ingredients.

$\checkmark \quad$ Microsponges can improve product elegance.

$\checkmark$ Microsponges can improve bioavailability of the drugs.

$\checkmark$ Microsponges have superior formulation flexibility.

\section{Microemulsions}

Microemulsions are clear, stable, isotropic liquid mixtures of oil, water and surfactant, frequently in mixture with a co-surfactant. The aqueous phase may also contain salt(s) and/or other ingredients, and the "oil" may also truly be a complex mixture of exclusive hydrocarbons and olefins. In contrast to regular emulsions, microemulsions form upon simple mixing of the components and do not require the high shear conditions generally used in the formation of ordinary emulsions. The two basic types of microemulsions are direct (oil dispersed in water, $\mathrm{o} / \mathrm{w}$ ) and reversed (water dispersed in oil, w/o). In ternary systems such as microemulsions, where two immiscible phases (water and 'oil') are present with a surfactant, the surfactant molecules may also form a monolayer at the interface between the oil and water, with the hydrophobic tails of the surfactant molecules dissolved in the oil phase and the hydrophilic head groups in the aqueous phase. As in the binary systems (water/surfactant or oil/surfactant), self-assembled structures of exclusive types can be formed, ranging, for example, from (inverted) spherical and cylindrical micelles to lamellar phases and bi-continuous microemulsions, which may also coexist with predominantly oil or aqueous phases [74]. 


\section{Advantages of micremulsions}

$>$ Microemulsions are thermodynamically stable system and the stability allows self-emulsification of the system.

Microemulsions act as super-solvents for drug. They can solubilize both hydrophilic and lipophilic drugs including drugs that are relatively insoluble in both aqueous and hydrophobic solvents.

$>$ Use of microemulsion as delivery systems can improve the efficacy of a drug, allowing the total dose to be reduced and thus minimizing side effects.

> The dispersed phase, lipophilic or hydrophilic (oil in-water, $\mathrm{O} / \mathrm{W}$, or water-in-oil, W/O microemulsions) can act as a potential reservoir of lipophilic or hydrophilic drugs, respectively. Drug release with pseudo-zero-order kinetics can be obtained, depending on the volume of the dispersed phase, the partition of the drug and the transport rate of the drug.

\section{Microneedles}

Microneedles (MNs) have been studied by means of various researchers for delivering drug through the transdermal route and for overcoming the limitations of the conventional approaches. Microneedle device consists of needles of micron size, which are arranged on a small patch. Considering the issues of the hypodermic needle and the transdermal patch, microneedle drug delivery system was developed and is thought to be the hybrid of both. The most important problem related with transdermal technological knowhow is that many of the drugs are not capable to cross the pores and skin at the required rate integral for the therapeutic action. Researchers have developed a refined technological know-how the use of microneedles, which permit hydrophilic high molecular weight compounds to enter into the stratum corneum. Administration of drugs using the microneedle device allows the drug molecules to cross the stratum corneum layer, hence allowing more drug molecules to enter the skin. The characteristic facts of this technology are the faster onset of action, better patient compliance, self-administration, improved permeability and efficacy. Large molecules can be administered. First-pass metabolism is avoided. Decreased microbial penetration as compared with a hypodermic needle, the microneedle punctures only the epidermis and enhanced drug efficacy may result in dose reduction [75].

\section{Microparticles}

Microparticles are a type of drug delivery systems where the particle size ranges from one micron (one thousandth of $\mathrm{mm}$ ) to a few $\mathrm{mm}$. This microencapsulation technology allows protection of drug from the environment, stabilization of sensitive drug substances, elimination of incompatibility, or masking of unpleasant taste. Hence, they play an important role as drug delivery systems aiming at improved bioavailability of conventional drugs and minimizing side effects [76].

\section{Microballoons}

Microballoons are gastro retentive drug-delivery systems with noneffervescent approach. Microballoons (Hollow microsphere) are in strict sense, empty particles of spherical shape without core. These microspheres are generally free flowing powders comprising of proteins or synthetic polymers, ideally having a size less than 200 micrometer. Microballoons are considered as one of the most beneficial buoyant systems with the special advantages of multiple unit systems as well as better floating properties, because of central hollow area interior the microsphere. Novel methods concerned in their preparation include easy solvent evaporation method, emulsion-solvent diffusion method, single emulsion technique, double emulsion technique, phase separation coacervation technique, polymerization technique, spray drying and spray congealing technique and hot melt encapsulation method. The gradual release of the drug at desired rate and higher floating properties in most cases depends on the kind of polymer, plasticizer and the solvents employed for the preparation. Polymers such as polylactic acid, Eudragit R S and hydroxy propyl methyl cellulose acetate are used in the formulation of hollow microspheres, and the release of drug can be modulated by using optimizing polymer concentration and the polymer-plasticizer ratio.
Advantages such as reduced dosing frequency and thereby improve the patient compliance; better drug utilization will improve the bioavailability and reduce the incidence or intensity of adverse effects, and despite the first-pass pass effect because fluctuation in plasma drug concentration is avoided, a desirable plasma drug concentration is maintained by continuous drug release. Hollow microspheres are used to decrease material density and Gastric retention time is increased because of buoyancy. Site-specific drug delivery to stomach can be achieved [77].

\section{Microchips}

Microchip drug delivery system is the most wonderful system of delivering the drug for a great span of time without the intervention of the patient to whom it is fixed. It consists of varied number of sockets containing drug (generally ranging from 50-300) which release the drug at the fixed intervals each at a time. The microchip delivery system consists of a substrate containing more than one reservoir capable of holding chemical substances in the solid liquid, or gel form. Each reservoir is capped (i.e. with a conductive membrane) and wired with the final circuitry controlled by a microprocessor. This central processor should be able to actively control electrically the exact time of release and the amounts of drugs dispersed through controlling the dissolution of the gold membrane. The system should be reasonable to manufacture by standard micro fabrication techniques and still be cost-effective [78].

\section{Syrups}

Syrups are concentrated solutions of sugar such as sucrose in water or other aqueous liquid. Due to sweetness, can masks the taste of salty and bitter tablets and therefore serve as fine tasting automobile. Used as care for pediatric use due to their excessive viscosity and the "smoothness" and mouth feel quality. Enhance the flavor Due to the wide kind of flavors of syrups which include orange, lemon, peppermint, those are broadly acceptable.

- Simple syrups: when water is used alone for making syrup.

- Medicated syrup: Syrup with some medicinal substance.

- Flavored syrup: Syrup with some aromatic or pleasantly flavored substances and is intended to be used as a vehicle or flavor for prescription.

\section{Suspensions}

A Pharmaceutical suspension is a coarse dispersion in which interior segment is dispersed uniformly at some point of the external phase. The internal phase consisting of insoluble strong particles having a specific range of size which is maintained uniformly throughout the suspending vehicle with aid of single or combination of suspending agent. The external phase (suspending medium) is generally aqueous in some instance, may also be an organic or oily liquid for non oral use.

Deflocculated suspension: In this system, solids are present as individual particles. They also exhibit aggregation, but comparatively at a slower rate than the flocculated particles. These systems have a shorter shelf life, but have greater bioavailability when compared to flocculated systems.

Flocculated suspension: In this system particles aggregate themselves by chemical bridging. These flocs are light, fluffy conglomerates which are held together by weak van Waals forces of attraction. Aggregation is achieved by adding flocculating adding flocculating agents. For instance, by the addition of more anions on to positively charged deflocculated particles flocculation can be achieved. This system possesses better physical stability characteristics, because the dissolution of flocs is a prerequisite for drug absorption [79].

\section{Emulsions}

Emulsions are two-phase system in which the dispersed phase is also liquid. Emulsion are defined as thermodynamically unstable systems consisting of at least two immiscible liquid phases, one of which is dispersed as globules the other liquid phase. Large number of emulsion is present in nature. Examples are milk, rubber latex, 
crude oil etc. Emulsion should be used when both phases, dispersed and continuous, are liquids. In an emulsion, one liquid (the dispersed phase) is dispersed in the other (the continuous phase). Examples of emulsions include vinaigrettes, homogenized milk, and some cutting fluids for metal working.

Water-in-Oil Emulsion: An emulsion is referred to as water-in-oil, if the dispersed phase (Internal phase) is water and the continuous phase (dispersed medium) is oil. Examples are butter, salad dressings. $w / o$ emulsion are generally meant for external use, though a few examples of internal use are available.

Oil-in-Water Emulsion: An emulsion is referred to as oil-in-water, if the dispersed phase (internal phase) is oil and the continuous phase (dispersed medium) is an aqueous base. These types of emulsion are meant for both internal and external use [80, 81].

\section{Multiple emulsions}

Multiple Emulsions are complex vehicle systems in which o/w and $\mathrm{w} / \mathrm{o}$ emulsions exist in a single system. Lipophilic and hydrophilic surfactants are exploited for stabilizing multiple emulsions. Waterin-oil emulsions can be stabilized by lipophilic (oil-soluble, low HLB) surfactants, while o/w systems are stabilized by hydrophilic (watersoluble, high HLB) surfactants. Multiple emulsions are "emulsions of emulsions," in wherein the drops of the dispersed phase themselves contain smaller dispersed droplets of a miscible liquid. Every dispersed globule in the double emulsion makes a vesicular structure with single or multiple watery compartments divided from the aqueous phase via an oil phase layer. In multiple emulsion system, solute has to transverse from inner miscible phase to outer miscible phase by the middle immiscible organic phase; it is also known as liquid membrane system. There are two important types of multiple emulsions: $\mathrm{w} / \mathrm{o} / \mathrm{w}$ and $\mathrm{o} / \mathrm{w} / \mathrm{o}$ double emulsions. Multiple emulsions are mainly used in cosmetics, pharmaceuticals, and food. Due to their fine texture, they exhibit a smooth touch upon application. In cosmetics, they can protect an active ingredient from degradation and release it at a controlled rate. They can act as an internal depot and entrap compounds from the outer diluted continuous phase into the inner space [82].

\section{Liniments}

Liniment is a liquid that you rub into the skin in order to reduce pain or relieve stiffness. Liniments can be rubbed into the skin to relieve aches from arthritis and stiffness in muscles. A liniment is usually in the form of a thin liquid applied to the skin. Liniment is a medicated topical preparation for application to the skin. Sometimes called balm or heat rubs, liniments are of a similar or greater viscositythan lotions and are rubbed in to create friction, unlike lotions, ointments or creams, but patches, sticks and sprays are also available [83].

\section{Ointments}

Ointments are viscous, semisolid preparations containing both dissolved and suspended purposeful ingredients. The ointment base needs to be heated to above its melting temperature prior to the addition of the other ingredients. Low-shear or blending speed is generally used when the ointment bases or completed formulation in cold/thick. Mixing speed and shear can be elevated while the ointment base is liquid, to uniformly disperse the practical ingredients. Mixers used for ointments generally rent dual-motion counter-rotating blades with side scrapers, to maintain the fabric in constant motion and provide efficient warmness transfer from the partitions of the mixing vessel. External powder educators may be used to incorporate stable ingredients. All ointments consist of a base which chiefly acts as a carrier for the medicaments. The nature of the base also controls its performance. Hence selection of ointment base is very important aspect of their formulation. For scientific understanding of per-cutaneous absorption of ointment bases it is essential to get familiar with skin structure in relation to drug absorption. They provide means of site specific application of drug on affected area, which avoids unnecessary non target exposure of drug thereby avoiding side effects. They avoid first pass metabolism of drug. This is the convenient method for unconscious patients having difficulty in oral administration. Comparatively they are chemically more stable and easy to handle than liquid dosage forms. They are suitable dosage forms for bitter taste drugs [84].

\section{Gels}

Gels are described as semi rigid systems wherein the movement of the dispersing medium is restricted through an interlacing three dimensional networks of particles or solvated macromolecules of the dispersed phase.

The word "gel" is derived from "gelatin" and both "gel" and "jelly" can be drawn again to the Latin gelu for "frost" and gel are, meaning "freeze" or "congeal". This origin shows the important idea of a liquid setting to a solid-like material that does not flow, however is elastic and retains some liquid characteristics. Use of the term "gel" as a class originated at some point of the overdue 1800s as chemists tried to classify semisolid substances according to their phenomenological characteristics instead of their molecular compositions. At that time, analytical methods wished to determine chemical structures have been lacking. In pharmaceutical applications, water and hydro-alcoholic solution is most common many polymer gels showcase reversibility between the gel state and sol, which are the fluid segment containing the dispersed or dissolved macromolecule.

However, the formation of some polymer gels is irreversible because their chains are covalently bonded. The three dimensional network formed in two-phase gels and jellies is formed by numerous inorganic colloidal clay. The formation of those inorganic gels is reversible.

Ideally, the gelling agent must be inert, safe and cannot react with other formulation constituents. The gelling agent should produce a sensible solid-like nature at the time of storage which is easily broken when exposed to shear forces produced by squeezing the tube, trembling the bottle or at the time of topical application. It should have suitable anti-microbial agent. The topical gel must not be sticky. The ophthalmic gel must be sterile. The apparent viscosity or gel strength increases with an increase in the effective crosslink density of the gel. However, a rise in temperature may increase or decrease the apparent viscosity, depending on the molecular interactions between the polymer and solvent. They exhibit the mechanical characteristics of the solid state. Each component is continuous throughout the system. There is high degree of attraction amongst the dispersed phase and water medium so the gels remain equally uniform upon standing and doesn't freely settle [85].

\section{Hydrogels}

Hydrogels that is polymer networks drastically swollen with water. Hydrophilic gels which are normally referred to as hydrogels are networks of polymer chains which might be sometimes observed as colloidal gels wherein water is the dispersion medium. Hydrogels are polymeric material that exhibits the capability to swell and retain a significant fraction of water within its structure, however will no longer dissolve in water. Hydrogels have received considerable attention within the past $50 \mathrm{y}$, due to their first-rate promise in a wide variety of applications.

The ability of hydrogels to absorb water arises from hydrophilic functional groups attached to the polymeric backbone, while their resistance to dissolution arises from cross-links between network chains. Many materials, each naturally taking place and synthetic, fits the definition of hydrogels. It has the highest absorption capacity (maximum equilibrium swelling) in saline. One can get the desired rate of absorption (preferred particle size and porosity) depending on the application requirement. Hydrogels has highest biodegradability without formation of toxic species following the degradation [86].

\section{Dendrimers}

The term dendrimer comes from the Greek word 'Dendron,' which means a tree. The synonym for Dendrimer is 'Arborols,' which also means a tree and 'Cascade molecule'. Dendrimers are repetitively branched molecules consisting of a monomer attached centre where a diameter in the range of 2 to $10 \mathrm{~nm}$ leads to a mono-disperse, treelike, star-like molecules. A dendron typically contains a single group called the focal point (branching points) that can be chemically 
handled. The first dendrimers Synthesis did by divergent synthesis approaches by Fritz Vögtle in 1978, R. G. Denkewalter at Allied Corporation in 1981, Donald Tomalia at Dow Chemical in 1983 and in 1985, and by George Newkome in 1985. In 1990 a convergent synthetic approach was introduced by Jean Fréchet. Polyamidoamines (PAMAM) were the first synthesized dendrimers. Simultaneously, the Newkome group documented synthesis of related macromolecules that they called "arborols" [87, 88].

\section{Advantages}

1. In the range of $1-100 \mathrm{~nm}$, dendrimers particle size in nanometer crosses the cell membrane easily.

2. Reduced clearance due to small scale through the ReticuloEndothelial System (RES).

3. Dendrimer is the ideal carrier for a core-protected dysfunctional drug.

4. It is monodispersed.

5. Dendrimer increases poorly soluble drug solubility.

6. There are several functional groups on the outer surface of dendrimers that can be used to attach vector devices to target specific body locations $[89,90]$.

\section{Types of dendrimer}

1. PAMAM Dendrimer

2. PAMAMOS Dendrimer

3. P PI Dendrimer

4. Tecto Dendrimer

5. Chiral Dendrimers

6. Hybrid Dendrimers

7. Liquid Crystalline Polymers

8. Amphiphilic Dendrimers

9. Micellar Dendrimers

10. Multiple Antigen Peptide Dendrimers

11. Frechet-Type Dendrimers

12. Multilingual Dendrimers [91-94]

\section{Nanoparticles}

There has been a growing interest in the use of nanoparticles for drug delivery applications in recent decades. Nanoparticles are particles of colloidal size with diameters ranging from 1-1000 nm and may contain, absorb or disperse drugs. A wide range of nanoparticles have been produced, consisting of a variety of materials, resulting in delivery systems that differ in their physicochemical properties and therefore in their applications [95, 96]. To date, a number of drug delivery mechanisms, including but not limited to liposomes, micelles, nanospheres, niosomes, nanocapsules, solid lipid nanoparticles, microemulsions and carbon nanotubes, have been studied. Such systems ' success is due in part to the several advantages they provide to distribute their product payload. The nano-sized versatility of these delivery systems allows them to be directly delivered into the systemic circulation without the possibility of blocking blood vessels. The size of the nanoparticle has been shown to be a significant factor in determining the particles in vivo fate. Researchers have shown that opsonization and subsequent macrophage recognition and phagocytosis are strongly correlated with particle size. Nanoparticles have the potential of addressing and remedying some of the most significant limitations of traditional chemotherapy, namely, its lack of specificity and narrow window of therapeutic efficacy. Nanoparticles are colloidal carriers with dimensions on the nano scale $\left(10^{-9} \mathrm{~m}\right)[97,98]$.

\section{Advantages}

1. Nanoparticles drug carriers have higher stability.
2. Nanoparticles have higher carrier efficiency.

3. Facility of integration of both hydrophilic and hydrophobic substances.

4. Nanoparticles are biodegradable, non-toxic and can be stored for longer periods.

5. Nanoparticles reduce dosage frequency and have higher dosage frequencies.

6. Nanoparticles can also be used for controlled drug delivery.

\section{Liposomes}

Liposomes are composed of amphiphilic molecules consisting of polar as well as non-polar components which form colloidal particles. This selfassembly produces a spherical structure that includes the polar components of the molecule and the non-polar components that touch the non-polar world. The most popular liposome distinction is the number of lipid bilayers in the colloidal form, with unilamellar liposomes containing one lipid bilayer and multiple liposomes with multiple lipid bilayers. Because of their amphiphilic nature, liposomes can encapsulate polar as well as non-polar compounds for delivery (Lasic, 1998). For many purposes, liposomes are desirable among drug delivery applications, including their similarity to both structure and composition of cell membranes. In addition, liposomes can easily be produced with amphiphilic molecules that are non-toxic, non-immunogenic, normal and biodegradable (Haley and Frenkel, 2008; Lasic, 1998). The size of a liposome ranges from $20 \mathrm{~nm}$ up to several micrometers [99-101].

\section{Advantages}

1. Providing preferential passive targeting for tumor tissues.

2. Increased efficacy and therapeutic index.

3. Increased stability by encapsulation.

4. Reduction in encapsulating agent toxicity.

5. Increased pharmacokinetic effects.

6. Used as carriers for controlled and sustained drug delivery.

7. Can be converted into different sizes.

\section{Classification of liposomes}

1. Multilamellar vesicle (MLVs)-This consists of several bilayers with a size ranging from $100 \mathrm{~nm}-20 \mathrm{~m}$.

2. Small unilamellar vesicles (SUVs)-This consists of a single lipid bilayer with a dimeter varying from $20-100 \mathrm{~nm}$.

3. Large unilamellar vesicles (LUVs)-Consists of a single bilayer with a diameter varying from $0.1-1 \mathrm{~m}$.

4. Multivesicular vesicles (MVVs)-It consists of vesicles ranging from $100 \mathrm{~nm}$ to $20 \mathrm{~m}$ in size.

\section{Transfersomes}

The name is derived from the Latin word 'transfere' meaning 'to carry across' and the Greek word 'soma' for a 'body'. Transferosomes are a particular type of liposomes that consist of edge activator and phosphatidylcholine [102]. They are flexible, malleable vesicles designed to improve active agent delivery. Transferosome is a complex aggregate that is highly adjustable, responsive to stress. Transferosomes have a joint infrastructure of hydrophobic and hydrophilic molecules and can therefore provide accommodation drug molecules with extensive range of solubility [103]. Without observable loss, transferosomes can deform and move through narrow constriction from 6 to 11 times lower than their own diameter $[104,105]$. This high deformability gives intact vesicles a greater penetration. Tranferosomes have a high efficiency of trapping, which is almost $90 \%$ for lipophilic drugs. Transferosomes protect the encapsulated medication from metabolic degradation. These have been commonly used as a carrier for various proteins, anti-cancer drugs, anti-fungal drugs, analgesics, anaesthetics, corticosteroids, sex hormone, insulin, albumin, etc. with the brilliant delivery properties of transferosomes $[106,107]$. 


\section{Nanospheres}

A polymeric nanosphere can be characterized as a matrix-type, solid colloidal particle in which drugs are dissolved, trapped, encapsulated, chemically bound or adsorbed to the polymer matrix of the constituent [108-110]. Usually, these particles are larger than micelles with diameters between 100 and $200 \mathrm{~nm}$ and can also show substantially more polydispersion [111]. The main aims of developing the Nanospheres as a target delivery system to monitor the particle size and the release of pharmacologically active agents to achieve the site specific action of the drug at the therapeutically optimal rate and dosage regimen $[112,113]$.

\section{Advantages}

1. Due to their extremely small volume, nanospheres can easily pass through the smallest capillary vessels $[114,115]$.

2. We should prevent rapid phagocyte removal in order to prolong the length of the bloodstream.

3. It is easy for nanospheres to penetrate cells and tissue gaps to enter target organs, eg. Liver, spleen, liver, lymph and spinal cord.

4. It shows the property of the controlled release.

5. Site-specific targeting by adding the ligands to the sphere's surface.

6. Each path, including oral, nasal, parenteral, etc, can be easily administered.

7. A significant advantage of nanospheres is also the elimination of toxicity [116].

\section{Nanoemulsion}

Nanoparticle formulation is effectively based on nanometric-scaled emulsion, so-called nano-emulsions, the study of nanoparticle formulation has to include knowledge of nanoemulsion formation governing phenomena. Nano-emulsions are nanometric-sized emulsions, typically exhibiting diameters of up to $500 \mathrm{~nm}$. Nanoemulsions are also often referred to as miniemulsions, finedispersed emulsions, submicron emulsions and so on, but are all characterized by high suspension stability due to their very small size, which is mainly the result of substantial steric stabilization between droplets, which explains why the Ostwald ripening process is the only adapted droplet destabilization process. Consequently, nano-emulsion systems can be viewed as a blueprint for the generation of nanoparticles, even though these two phases can often be merged into one. Thus, the countless variants of the formulation of nanoparticles are based mainly on three different groups of methods for nanoemulsion generation, i.e. high-energy methods, low-energy spontaneous emulsification process. The inverse temperature (PIT) is low-energy step process [117-119].

\section{Advantages}

1. Ease of scale-up and limited batch-to-batch variability.

2. Narrow scale nanoparticulate drug distribution.

3. Flexibility in the management of product quality.

4. Applied selectively to thermolabile compounds.

5. Taste masking.

6. Non toxic and non irritant.

7. Enhances the bioavailability of the drug.

\section{Solid lipid nanoparticles}

In 1991, Solid lipid nanoparticles were introduced and they represent different carrier systems to traditional carriers such as liposomes, micro and nanoparticles, emulsion [120]. As a novel colloidal drug carrier for intravenous applications, nanoparticles made from solid lipids are attracting great attention because they have been proposed as an alternative particulate carrier system [121]. Solid Lipid Nanoparticles are colloidal submicron carriers ranging from 50-1000 $\mathrm{nm}$, consisting of physiological lipid, distributed in water or in an aqueous surfactant solution [122]. SLN offers unique properties such as small size, large surface area, high drug loading and step interaction at the interface, and is desirable for their potential to improve pharmaceutical performance. The use of solid lipids as the drug delivery matrix content is well known from lipid pellets for oral drug delivery (e. g. Mucosolvanw retardation capsules) [123].

\section{Benefits of solid lipid nanoparticles}

1. Control and target drug release from the system.

2. Brilliant biocompatibility

3. Increase steadiness of pharmaceuticals

4. Superior drug content

5. Manufacturing is much easier than biopolymeric nanoparticles.

6. Special solvent not required [124].

\section{Nanostructure lipid carrier}

Nanostructure Lipid Carriers are the second generation lipid nano carriers consisting of solid lipid matrix filled with liquid lipids. NLCs are able to firmly immobilize drugs and prevent particles from coalescing as opposed to emulsions by virtue of the solid matrix Mobility of the drug molecules incorporated in the solid phase is also significantly reduced. Additionally, droplets of liquid oil in the solid matrix increase the drug load capacity relative to SLNs. NLCs also have benefits over polymeric nanoparticles, including low toxicity, biodegradability, drug safety, controlled release and avoidance during development of organic solvents. NLCs have been studied intensively as hydrophilic and hydrophobic drug delivery carriers [125].

\section{Niosomes}

Niosomes are vesicles that consist mainly of non-ionic hydrated surfactants, in addition to cholesterol (CHOL) or its derivatives in many cases. The specific structures of niosomes allow both hydrophilic and lipophilic substances to be encapsulated. This can be done by encapsulating hydrophilic substances in the vesicular aqueous core or adsorbing them on the bilayer surfaces while the lipophilic substances are encapsulated by partitioning them into the bilayer's lipophilic domain. Thin lipid film or lipid cake is hydrated and liquid crystalline bilayers stacks are liposome-forming, swelling, and flowing. Agitation divides and self-associates the hydrated lipid sheets to form vesicles, preventing water contact with the bilayer's hydrocarbon center at the edges. In recent years, niosomes have been one of the prominent vesicles in all vesicular systems, taking on a great deal of interest as potential drug delivery systems for various routes of administration. This is because niosomes do not have the many drawbacks that others have and are a very effective drug delivery system with various applications; niosomes are capable of clogging specific types of drugs, genes, proteins and vaccines [126].

\section{Advantages}

1. Niosomes are osmotically active, chemically stable and have a long storage time compared to liposomes.

2. Their surface formation and alteration is very simple due to their hydrophilic head functional groups.

3. They are highly compatible with biological systems and have low toxicity due to their non-ionic nature.

4. They are also biodegradable and non-immunogenic.

5. They can trap lipophilic drugs in aqueous compartments into bilayer vesicular membranes and hydrophilic drugs.

6. We can enhance the therapeutic efficacy of drug molecules by shielding the drug from the biological environment, leading to enhanced availability and controlled drug delivery by reducing drug effects on target cells in selected carriers and delaying circulation clearance in sustained drug delivery.

7. Unlike phospholipids, surfactant handling does not require special precautions and conditions.

8. Improves product bioavailability in the oral and skin. 
9. Niosomes can improve the absorption of certain drugs across cell membranes, locate them in targeted tissues and avoid the reticuloendothelial system [127-129].

\section{Gold nanoparticles}

Nanocarriers have developed a novel platform for the delivery of therapeutic agents to specific targets [130]. Many delivery vehicles have been developed over the last decade based on various nanomaterials, such as polymers [131], dendrimers [132], liposomes [133], nanotubes [134] and nanorods [135]. Gold nanoparticles (GNPs) have recently emerged as an attractive candidate for delivering unique payloads within their goals. The payloads may be small drug molecules or large biomolecules, such as proteins, DNA, or vide post RNA [136, 137]. Such therapeutic agents ' performance release is a requirement for effective therapy. The release may be caused by internal stimuli (e. g. glutathione (GSH) [138] or $\mathrm{pH}$ [139]) or external stimuli (e. g., light [140]). For example, in the monolayer, a gold nanoparticle with a core diameter of $2 \mathrm{~nm}$ could in principle be combined with average 100 molecules to available ligands. Zubarev et al. recently succeeded in combining average 70 molecules of paclitaxel, a chemotherapy drug, with a GNP with a core diameter of $2 \mathrm{~nm}$.

\section{Quantum dots (QDs)}

Quantum dots are tiny semiconductors particles a few nanometers in size, having optical and electronic properties that differ from large particles due to quantum mechanics. They are central topics in nanotechnology. When UV light illuminates the quantum dots, a quantum dot electron can be excited to a higher energy state. This process corresponds to the transition of an electron from the valance band to the conductance band in the case of a semiconducting quantum point. The excited electron can drop back into the valence band and release its energy by light emission. The light's color depends on the difference in energy between the conductivity and the valance band. Nanoscale semiconductor materials tightly contain either electrons or electron holes in the language of materials science. Quantum dots are sometimes referred to as artificial atoms, emphasizing their singularity, having binding, discrete electronic states, such as atoms or molecules that occur naturally. It has been shown that the electronic wave functions in quantum dots are similar to those in the real atoms. By coupling two or more such quantum dots, an artificial molecule can be made, hybridizing even at room temperature. Quantum dots have intermediate properties between large semiconductors and discrete atoms or molecules. Their optoelectronic properties change as a function of size and shape. Larger QDs with diameter of 5-6 nm emit longer wavelengths with colors like orange or red. Smaller QDs (2-3 $\mathrm{nm}$ ) emit shorter wavelengths, resulting in blue and green colors. However, the specific colors vary depending on the exact composition of the QD [141].

Example: For in vivo use of semiconductor quantum dots are imaging of tumor vasculature, imaging of tumor-specific membrane antigens, as well as imaging of sentinel lymph nodes. Multicolor fluorescence imaging of cancer cells can be accomplished by systemic injection of quatum-dot based multifunctional nanoprobes [142].

\section{Nanoshells}

Nanoshells are nanoparticles that are optically tunable and consist of a dielectric core and a shell of thin metal. These particles can primarily be designed to scatter or absorb light based on the dimensions of the core and shell. A larger core results in a greater contribution of scattering to total extinction, whereas a smaller core typically includes absorbing properties. The location within the spectrum of peak extinction depends on the core radius ratio to shell thickness. A thinner shell causes the peak extinction to shift to longer wavelengths, whereas a thicker shell produces a peak blueshift [143]. Due to their ability to disperse or absorb light, nanoshells have great potential for both imaging and therapeutic applications, specifically optical imaging and photothermal tumor ablation. Other applications include tissue welding [144] and probes for antigen detection in whole blood [145].

\section{Nanotues}

Graphite is a well-known example of this, but now carbon can form closed and open cages with a honeycomb arrangement beside graphite [146]. Graphene is known in the list of carbon nanomaterials as 2D single graphite layer. Graphene is stronger than diamond material because it contains $\mathrm{sp}^{2}$ hybridisation that is stronger than diamond $\mathrm{sp}^{3}$ hybridisation [147]. Carbon nanotubes are among the most exciting areas of research in recent decades [148]. Carbon nanotubes consist of carbon, and it is a material shaped by a tube. It has too small a diameter and is measured by nanoscale.

\section{Parenteral drug delivery system}

The term parenteral formed outside from the Greek word "para" and intestine "enterone". Parenterals are sterile solutions or medication suspension in aqueous or oily vehicles. Parenteral medications are delivered directly into lungs, muscles or under the skin, more advanced tissues such as the spinal cord. Term used for any fluid/drug that does not use the alimentary canal to enter the body tissue. Pyrogens, substances causing fever, primarily lipopolysaccharides formed by microorganism metabolism; they may be insoluble, soluble or colloidal. Parenteral administration routes usually start more quickly than other administration routes $[149,150]$.
Advantages
a) Useful for patients who are unable to take drugs orally.
b) Fast start of action.
c) Useful in emergency situations.
d) Continuous drug delivery.
e) Prevent metabolic first-passing
f) Can inject drugs directly into the tissue
g) Can be used to administer fluids
h) Electrolytes or nutrients in hospitals
i) Outpatient infusion centers and home health facilities
j) Better bioavailability

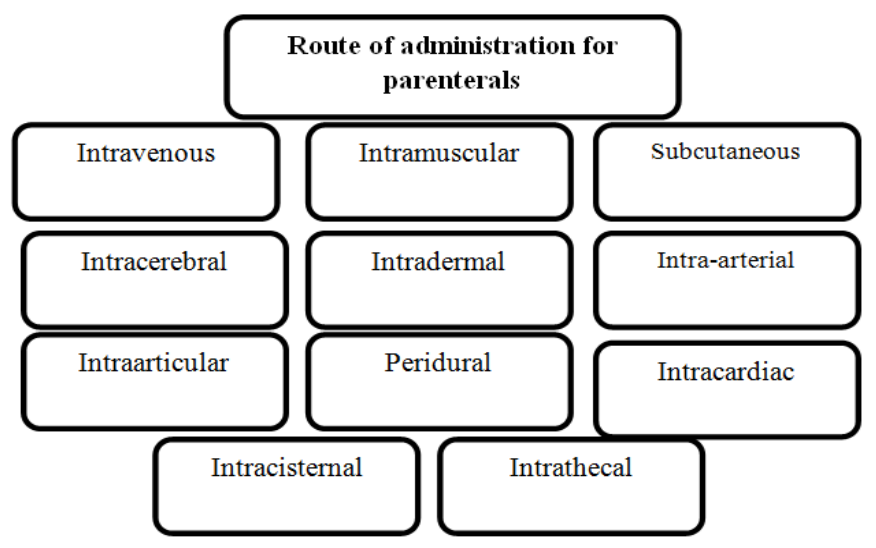

Fig. 1: Different types of routes for parenteral drug delivery 


\section{Classification of parenterals}

1. Small volume parenterals (SVPs)

2. Large volume Parenteral (LVPs)

1. Small volume parenterals-A small intravenous injection volume is added to an injection packed in containers defined as $100 \mathrm{ml}$ or less.

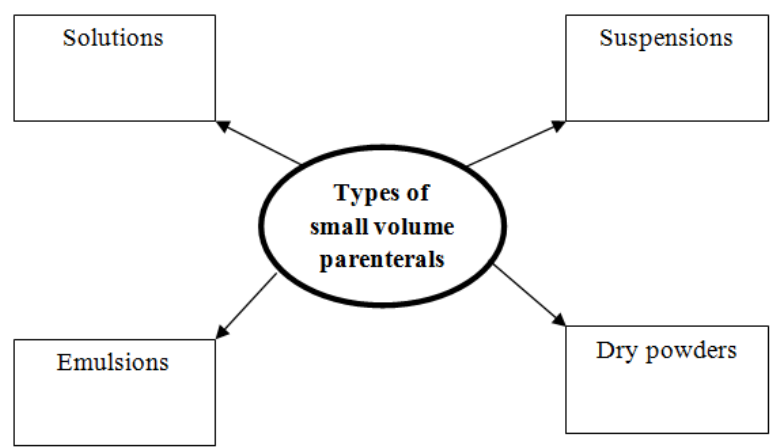

Fig. 2: Different types of small volume parenterals

\section{Large volume parenterals}

These are parenterals intended to supply air, calories, electrolytes. These are sterile, non pyrogenic, free from particulate matter injections having volume $101-1000 \mathrm{ml}$.

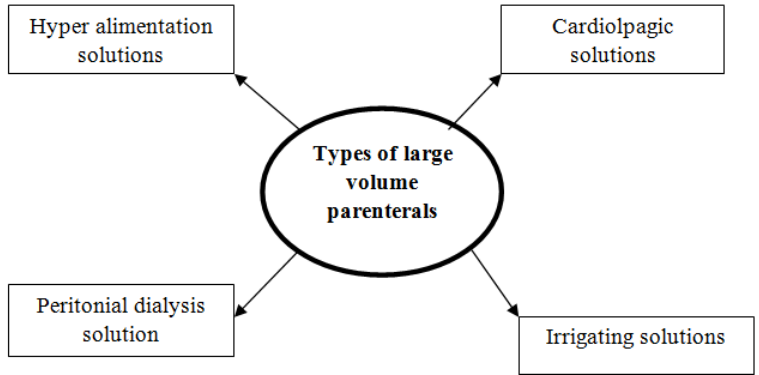

Fig. 3: Different types of large volume parenterals

\section{Ethosomes}

Touitou et al. discovered and created ethosomes in 1997 [151]. They can be described as non-invasive new delivery carriers that allow drugs to be transferred to and through deep skin layers and/or systemic circulation. Ethosomes are vesicular carriers consisting of hydroalcoholic or hydro/alcoholic/glycolic phospholipids with a relatively high concentration or combination of alcohols [152]. These are soft, malleable vesicles that are tailored to improve the delivery of active agents. For many years, the vesicles are well known for their importance in cellular communication and particle transport. Vesicles would also allow the release rate of the drug to be regulated over an extended period of time, keep the drug protected from immune response or other removal mechanisms and thus be able to release the correct amount of drug and maintain the concentration steady for a long time. The size range of ethosomes varies from tens of nanometers $(\mathrm{nm})$ to microns $(\mu)[153,154]$.

\section{Benefits of Ethosomes}

1. Contains a mixture of non-toxic raw material.

2. Targeted drug delivery system.

3. Controlled drug delivery system.

4. The ethosomal technology is immediately available for marketing.
5. Good compliance with patients: the ethosomal drug is delivered in a semi-solid form (gel or cream) resulting in high patient compliance.

6. Ethosomal drug delivery system can be widely used in the fields of pharmaceutical, veterinary, cosmetic $[155,156]$.

\section{Pulsatile drug delivery systems}

Pulsatile drug delivery system is that system which releases the drug in 'pulse' form which means a 'lag time' before releasing the drug and then complete release of the drug from the system. The release of the drug form these systems are mostly depend upon the environmental changes in vivo. Time controlled, stimuli induced, externally regulated systems are made to achieve this type of drug release profile. $\mathrm{pH}-$ dependent systems and micro flora dependent systems are the examples of pulsatile drug delivery systems. These types of systems are useful in various diseases like bronchial asthma, myocardial infarction, angina pectoris, arthritis and hypertension, because in these diseases, the level of hormones and other factors increases and decreases with time. So, pulsatile systems are very useful to control the attacks at that particular time $[157,158]$.

\section{Bucky balls}

In September 1985 Bucky balls were first discovered experimentally. Bucky balls are a fullerene form with Formula $\mathrm{C}_{60}$. It has a cage that resembles a soccer ball, consisting of twenty hexagons and twelve pentagons, with a carbon atom with one $\Pi$ bond and two $\sigma$ bonds at each corner of the structure to create a universal vertex [159]. Fullerenes are inert and hollow, and can be modified indefinitely. They are not absorbed when administered orally in water-soluble form; while on the i. v. Injection, they spread rapidly to different body tissues. They excrete via the kidney unchanged. It was found that the acute toxicity of water-soluble fullerenes was fairly low. All of these interesting properties offer the possibility of using fullerenes in biology and medicinal chemistry and promise a bright future as medicinal agents for fullerenes. Bucky balls are the third form of carbon, and have become the most popular science and technology molecules. Nowadays, bucky balls are a key topic in nanotechnology and industrial research because of their very practical. Fullerenes are already used in today's industry, mostly in cosmetics, where they play a significant role as antioxidants $[160,161]$.

\section{Lymphatic carrier drug delivery system}

The delivery of drugs and bioactive compounds via the lymphatic system is complex and depends on the nature of the system physiologically. The lymphatic path plays an important role in transporting extracellular fluid to preserve homeostasis and moving immune cells to injury sites, preventing first-pass metabolism and thus serving as a bypass route for compounds with lower bioavailability, i.e. those suffering from more hepatic metabolism. The lymph route also provides an option for the delivery of therapeutic molecules, such as cancer treatment drugs and the human immunodeficiency virus, which can travel through the lymph system [162]. The targeting of the lymph system through subcutaneous, intestinal and pulmonary routes was assessed and subsequently used to enhance the lymph penetration and retention of drug molecules, minimize drug-related systemic toxicity and increase the bioavailability of poorly soluble and unstable drugs [163].

\section{Intrauterine device (IUD)}

An intrauterine device (IUD) is a small T-shaped birth control device, which is placed in the woman's uterus to prevent pregnancy. IUDs are one form of long-acting reversible birth control (LARC). IUDs are safe and effective in adolescents as well as those who've not formerly had children. Once an IUD is removed, even after long-term use, fertility returns to normal rapidly. There are two types IUD

\section{Non hormonal (Copper containing IUD)}

Most copper IUDs have a T-shaped frame it wound be around with pure electrolytic copper wire and/or has copper collars (sleeves). 
The arms of the frame hold the IUD in place near the top of the uterus., copper acts as a spermicide within the uterus by increasing levels of copper ions, prostaglandins, and white blood cells within the uterine and tubal fluids. The increased copper ions in the cervical mucus inhibit the sperm's motility and viability, preventing sperm from traveling through the cervical mucus, or destroying it as it passes through. Copper can also alter the endometrial lining, but studies show that while this alteration can prevent implantation of a fertilized (blastocytes), it cannot disrupt one that has already been implanted. It is the most effective form of emergency contraception available. It works by preventing fertilization or implantation but does not affect already implanted embryos. It contains no hormones, so it can be used while breastfeeding and fertility returns quickly after removal. Copper IUDs also last longer and are available in a wider range of sizes and shapes compared to hormonal IUDs. The possibility of heavier menstrual periods and more painful cramps.

Hormonal IUDs work by liberating a small amount of drug (levonorgestrel). Each kind varies in size, amount of levonorgestrel released, and duration. The primary mechanism of action is making the inside of the uterus uninhabitable for sperm. They can also thin the endometrial lining and potentially impair implantation but this is not their usual function. Because they fine the endometrial lining, they can also reduce or even prevent menstrual bleeding $[164,165]$.

\section{CONCLUSION}

Different drug delivery systems have been used to provide health benefits to the society since decades. As the world of medicine grows, the newer system of delivering the drugs has been discovered to solve the problems like safety and efficacy of the newer invented active pharmaceutical ingredients. Every coin has two sides just like every delivery system, but to avoid those limitations newer inventions come into this world. The newer systems then avoid the limitations of prior systems. In the end, we can say that the allopathic system of medicines is growing towards new heights.

\section{ACKNOWLEDGEMENT}

Amar Shaheed Baba Ajit Singh Jujhar Singh Memorial College of Pharmacy, Bela, Rupnagar, Punjab, India.

\section{FUNDING}

Nil

\section{AUTHORS CONTRIBUTIONS}

All the authors have contributed equally.

\section{CONFLICTS OF INTERESTS}

\section{Declared none}

\section{REFERENCES}

1. Gosh Subhajit, Murthy PN, Joshi Hanumanthachar. A literature review on various ayurveda dosage form. J Sci Yoga Nat 2018;5:19-23.

2. Indian Pharmacopoeia. Government of india ministry of health and family welfare, the controller of publication Delhi. Indian Pharmacopoeia 2018;2:1118-21.

3. Salunkhe A Atish, Jagtap A Vaibhavkumar, Md Usman, Md Rageeb, Nagaich Upendra. A textbook of industrial pharmacy-I. S. Vikas and Company (Medical Publishers); 2019. p. 25-32.

4. Masaki Ando, Rina Ito, Yuichi Ozeki, Yukiharu Nakayama, Toshitaka Nabeshima. Evaluation of a novel sugar coating method for moisture protective tablets. Int J Pharma 2007;336:319-28.

5. Kirsch John D, Drennen James K. Determination of film-coated tablet parameters by near-infrared spectroscopy. J Pharm Bio Anal 1995;13:1273-81.

6. Ofori Kwakye Kwabena, Fell John T. Biphasic drug release from film-coated tablets. Int J Pharm 2003;250:431-40.

7. Chambliss Walter G, Chambliss Diana A, Cleary Robert W, Jones Alan B, Harland Ernest C, Kibbe Arthur H. Development and evaluation of enteric-coated penicillamine tablets. J Pharm Sci 1984;73:1215-9.
8. Shukla Dali, Chakraborty Subhashis, Singh Sanjay, Mishra Brahmeshwar. Mouth dissolving tablets II: an overview of evaluation techniques. Sci Pharm 2009;77:327-41.

9. Rasheed Shaik Harun, Vani P Sandhya, Gajavalli Silpa Rani, Hussain Sk Shahul, Venugopal B, Ravikiran T, et al. Formulation and evaluation of chewable tablets of mebendazole. Int J Pharm W Res 2011;2:183-9.

10. Rishikesh, Bhuyian Mohiuddin Ahmed, Dewan Irin, Ghosh Drishti Rani, Islam Md Asraful. Immediate release drug delivery system (tablets). Int Res J Pharm A Sci 2012;2:88-98.

11. Chittaranjan Andrade. Sustain release, extended release and other time release formulations in neuropschyiatry. Clin Prarm Pharm 2015;76:e995-9.

12. Maheshwari R, Jain V, Ansari R, Mahajan SC, Joshi G. A review on lozenges. Br Biomed Bull 2013;1:35-43.

13. Shinde G, Kadam V, Kapse GR, Jadhav SB, Zameeruddin MD, Bharkad B. A review on lozenges. Indo Am J Pharm Res 2014;4:566-71.

14. Pothu R, Rao Y. Lozenges formulation and evaluation. Int J Adv Pharm Res 2014;5:290-8.

15. Kaur R, Kaur S. Role of polymers in drug delivery. J Drug Delivery Ther 2014;4:32-6.

16. Aulton EM. Pharmaceutics. $3^{\text {rd }}$ ed. Compressed lozenges; 2007. p. 457.

17. Pothu R, Rao Y. Development and in vitro evaluation of nicotine troches for smoking cessation. Asian J Pharm Clin Res 2014;7:68-75.

18. Mehta RM. Pharmaceutics. $1^{\text {st }}$ ed. Vallabh Prakashan publishers; 1997. p. 160-2.

19. Loyd V Allen. Suppositories as drug delivery system. J Pharm Care Pain Symptom Control 1997;5:17-26.

20. VR Sirisha K, K Vijaya Sri, K Suresh, G Kamalakar Reddy, N Devanna. A review of pellets and pelletization process-a multiparticulate drug delivery system. Int J Pharm Sci Res 2013;4:2145-58.

21. Rabadiya Bhavisha, Rabadiya Paresh. A review: capsule shell material from gelatin to animal origin material. Int J Pharm Res Bio 2013;2:42-71.

22. Lachman Leon, Liberman Herbert A, K Joseph L. The theory and practice of industrial pharmacy. $3^{\text {rd }}$ ed. Varghese Publishing House edition; 1986. p. 374.

23. Fridrun Podczeck, Brian E Jones. $2^{\text {nd }}$ ed. The history of the medicinal capsule in pharmaceutical capsules; 2004.

24. Salunkhe A Atish, Jagtap A Vaibhavkumar, Md Rageeb, Nagaich Upendra. A textbook of industrial pharmacy-I. S. Vikas and Company (Medical publishers); 2019. p. 94.

25. Dhanpal Ramaiyan, Ratna J Vijaya. Ocular drug delivery system-a review. Int J Inno Dr Dis 2012;2:4-15.

26. Patel Ashaben, Cholkar Kishore, Agrahari Vibhuti, Mitra Ashim K. Ocular drug delivery systems: an overview. Wor J Pharm 2013;2:47-64.

27. Hardaker Lucy EA, Hatley Ross HM. In vitro characterization of the I-Neb adaptive aerosol delivery (AAD) system. J Aerosol Med Pulm Drug Delivery 2010;23 Suppl 1:S11-20.

28. Sharma Deepak, Sharma Amit, Garg Rajeev. Preparation, physicochemical evaluation and characterization of mucoadhesive buccal gels impregnated with benzydamine hydrochloride for the effective treatment of aphthous stomatitis: effect of different grades of HPMC polymer on in vitro and ex vivo performance. Drug Delivery Lett 2019;9:341-57.

29. Jaiswal SB, Brahmankar DM. Biopharmaceutics and pharmacokinetics, a treastise. $2^{\text {nd }}$ edition. Vallabh Prakashan, New Delhi; 2017.

30. Jain NK. Controlled and novel drug delivery systems. $1^{\text {st }}$ ed. CBS publishers, New Delhi; 2009.

31. Chien Yie W. Novel drug delivery system. $2^{\text {nd }}$ ed. Informa healthcare, NY; 2018. p. 50.

32. Deepak Sharma, Amit Sharma, Rajeev Garg. Design, development and in vitro/ex vivo evaluation of mucoadhesive buccal film of benzydamine hydrochloride for the effective treatment of aphthous stomatitis. Recent Pat Drug Delivery Formulation 2018;12:277-94.

33. Garg R, Gupta GD. Progress in controlled gastroretentive delivery systems. Trop J Pharm Res 2008;7:1055-66. 
34. Garg R, Gupta GD. Preparation and evaluation of gastroretentive floating tablets of silymarin. Chem Pharm Bull 2009;57:545-9.

35. Chokshi M Maulesh, Gupta Mohan Madan, Gupta Madhulika. Formulation and evaluation of gastroretentive floating tablet of ciprofloxacin hydrochloride. Int J Pharm Pharm Sci 2016;8:148-52.

36. Kissel T, Werner U. Nasal delivery of peptides: an in vitro cell culture model for the investigation of transport and metabolism in human nasal epithelium. J Controlled Release 1998;53:195-203.

37. Ridley D, Perkins AC, Washington N, Wilson CG, Wastie M, Flynn PO, et al. The effect of posture on nasal clearance of bioadhesive starch microspheres. STP Pharm Sci 1995;5:442-6.

38. Illum L, Hincal AA, Kas HS, Sumnu M. editors. Drug delivery systems for nasal application. Third Int Pharm Tech Sym; 1985.

39. Sarkar MA. Drug metabolism in the nasal mucosa. J Pharm Res 1992;9:1-9.

40. Brime B, Ballesteros MP, Frutos P. Preparation and in vitro characterization of gelatin microspheres containing levodopa for nasal administration. J Microencapsulation 2000;6:777-84.

41. Mygind N, Dahl R. Anatomy, physiology and function of the nasal cavities in health and disease. Adv Drug Delivery Rev 1998;29:3-12.

42. HM Courrier, N Butz, Th F Vandamme. Pulmonary drug delivery systems: recent developments and prospects. Crit Rev Ther Drug Carrier Syst 2002;19(4 Suppl 5):425-98.

43. Mishra Nidhi, Yadav Narayan Prasad, Rai Vineet Kumar, Sinha Priyam, Yadav Kuldeep Singh, Jain Sanyog, et al. Efficient hepatic delivery of drugs: novel strategies and their significance. Bio Res Int 2013;20:1-20.

44. Roitt Ivan M. Essential Immunology. $8^{\text {th }}$ ed. Blackwell Scientific Publications; 1994. p. 120-2.

45. Roitt Ivan, Brostoff Jonathan, Male David. Immuonology. $5^{\text {th }}$ ed. Mosby publishers; 1998. p. 281-2.

46. David HJ Bunka, Olga Platonova, Peter G Stockley. Development of aptamer therapeutics. Curr Opin Pharmacol 2010;10:557-62.

47. Brody Edward N, Gold Larry. Aptamers as therapeutic and tiagnostic agents. Rev Mol Biol 2000;74:5-13.

48. Agarwal Sudhir, Kandimalla Ekambar R. Antisense therapeutics: is it as simple as complementary base recognition? Mol Med Today 2000;6:72-81.

49. Akhtar Saghir, Juliano RL. Cellular uptake and intracellular fate of antisense oligonucleotides. Trends Cell Biol 1992;2:139-44.

50. Grove Mette, Mullertz Anette, Neilsen Jeanet Logsted, Pedersena Gitte Pommergaard. Bioavailability of seocalcitol II: development and characterisation of self-microemulsifying drug delivery systems (SMEDDS) for oral administration containing medium and long chain triglycerides. Eur J Pharm Sci 2006;28:233-42.

51. Date Abhijit A, Nagarsenker MS. Design and evaluation of selfnanoemulsifying drug delivery systems (SNEDDS) for cefpodoxime proxetil. Int J Pharm 2007;329:166-72.

52. Sharma Monika, Garg Rajeev, Sardana Satish. Enhanced release kinetics and stability of resveratrol loaded self nanoemulsifying delivery systems developed using experimental design. Cur Nanomed 2019;9:128-45.

53. Melief CJ, Van Hall T, Arens R, Ossendorp F, Van der Burg SH. Therapeutic cancer vaccines. J Clin Int 2015;125:3401-12.

54. Petrovsky, Nikolai, Aguilar, Julio César.Vaccine adjuvents: current state and future trends. Immunol Cell Biol 2004;82:488-96.

55. Sinha JK, Bhattacharya S. A textbook of immunology. Academic publishers; 2014. p. 318.

56. Badgett MR, Auer A, Carmichael LE, Parrish CR, Bull JJ. Evolutionary dynamics of viral attenuation. J Virol 2002;76:10524-9.

57. Moloney PJ. The preparation and testing of diphtheria toxoid (anatoxine-ramon. Am J Public Health 1926;16:1208-10.

58. Williamson ED, Eley SM, Griffin KF, Green M, Russell P, Leary $\mathrm{SE}$, et al. A new improved sub-unit vaccine for plague: the basis of protection. FEMS Immunol Med Microbiol 1995;12(3 Suppl 4):223-30.

59. Amidon Seth, Brown Jack E, Dave Vivek S. Colon-targeted oral drug delivery systems: design trends and approaches. AAPS PharmSciTech 2015;16:731-41.
60. Sung YK, Kim SW. Recent advances in the development of gene delivery systems. S K Biomater Res 2019;23:8.

61. Arruebo Manuel, Fernandez Pacheco Rodrigo, Ibarra M Ricardo, Santamaria Jesus. Magnetic nanoparticles for drug delivery. Int J Nanomed 2007;2:22-32.

62. Seelig A, Gottschlich R, Devant RM. A method to determine the ability of drugs to diffuse through the blood-brain barrier. Proc Natl Acad Sci USA 1994;91:68-72.

63. Shaikh Rahamatullah, Thakur Raghu Raj Singh, Martin James Garland, A David Woolfson, Ryan F Donnelly. Mucoadhesive drug delivery systems. J Pharm BioAllied Sci 2011;3:89-100.

64. Michael I Ugwoke, Remigius U Agu, Norbert Verbeke, Renaat Kinget. Nasal mucoadhesive drug delivery: background, applications, trends and future perspectives. Adv Drug Delivery Rev 2005;57:1640-65.

65. McClements DJ, Decker EA, Weiss J. Emulsion-based delivery systems for lipophilic bioactive components. J Food Sci 2007;72:109-24.

66. Numata Keiji, Kaplan David L. Silk-based delivery systems of bioactive molecules. Adv Drug Delivery Rev 2010;62:1497-508.

67. Verma K Rajam, Divi Murali Krishna, Garg Sanjay. Formulation aspects in the development of osmotically controlled oral drug delivery systems. J Controlled Release 2002;79(1 Suppl 3):7-27.

68. Brahmankar DM, Jaiswal Sunil B. Biopharmaceutics and pharmacokinetics a treatise. Vallabh prakashan publishers; 2009. p. 440-7.

69. Kaur LP, Garg R, Gupta GD. Development and evaluation of topical gel of minoxidil from different polymer bases in application of alopecia. Int J Pharm Pharm Sci 2010;2:43-7.

70. Shingade GM, Aamer Quazi Sabale PM, Grampurohit ND, Gadhave MV, Jadhav SL, Gaikwad DD. Review on: recent trend on transdermal drug delivery system. J Drug Delivery Ther 2012;2:66-75.

71. Kala D, Nair CR Sudhakaran. In vivo evaluation of budesonide microspheres for colon specific drug delivery. Int J Pharm Pharm Sci 2016;8:159-65.

72. Krishna Sailaja A, Jyothika M. A review on microcapsules. CIB Tech J Pharm Sci 2015;4:26-33.

73. Jyoti, Kumar Sandeep. Innovative and novel strategy: microsponges for topical drug delivery. J Drug Delivery Ther 2018;8:28-34.

74. Madhav S, Gupta D. A review on microemulsion based system. Int J Pharm Sci Res 2011;2:1889-99.

75. Waghulea Tejashree, Singh Gautam, Dubeya Sunil Kumar, Pandeya Murali Monohar, Gupta Gaurav, Singh Mahaveer, et al. Microneedles: a smart approach and increasing potential for transdermal drug delivery system. J Bio Pharm 2019;109:1249-58.

76. Kumar BP, Chandiran IS, Bhavya B, Sindhuri M. Microparticulate drug delivery system: a review. Ind J Pharm Sci Res 2011;1:19-37.

77. Kumar Ritesh, Kamboj Surbhi, Chandra Amrish, Gautam PK, Sharma VK. Microballoons: an advance avenue for gastroretentive drug delivery system-a review. UK J Pharma Bio 2016;4:29-40.

78. Singh RP, Sarju Nasit, Sharma Anil, Singh SG, Khunt Sanket. Microchip for drug delivery system: a review. J Appl Pharm Sci 2011;1:7-11.

79. Nutan MTH, Reddy IK. General principles of suspensions. Pharma Suspen; 2009. p. 39-65.

80. Subrahmanyam CVS. Textbook of physical pharmaceutics. Vallabh prakashan publishers; 2012. p. 366-98.

81. Khan Barkat Ali, Akhtar Naveed, Khan HMS, Waseem Khalid, Mahmood Tariq, Rasul Akhtar, Iqbal Muhammad, et al. Basics of pharmaceutical emulsions: a review. Afr J Pharm Pharm 2011;5:2715-25.

82. Sarika SL, Namita NP, Vijay NR, Savita S. An update review on recent advancements in multiple emulsion. Int J Res Sci Inno 2018;5:90-6.

83. Sinha RP, Mitra SK, Roy PK. Liniment a. b. c. poisoning. J Indian Med Assoc 1967;48:278-9.

84. Shelke Usha Y, Mahajan Ashish A. Review on: an ointment. Int J Pharm Pharm Res 2015;4:170-92.

85. Rathod HJ, Mehta DP. A review on pharmaceutical gel. Act Sci Int J Pharm Sci 2015;1:33-47. 
86. Enas MA. Hydrogel: preparation, characterization, and applications: a review. J Adv Res 2015;6:105-21.

87. Tomalia DA, Baker H, Dewald J, Hall M, Kallos G, Martin S, et al. A new class of polymers starburst-dendritic macromolecules. Polym J 1985;17:117-32.

88. Newkome GR, Yao ZQ, Baker GR, Gupta VK. Cascade molecules: a new approach to micelles. J Org Chem 2006;50:1985.

89. Landge DA, Shyale SS, Kadam SD, Shah DV, Katare YS, Pawar JB. Dendrimer: an innovative acceptable approach in novel drug delivery system. Pharm Int J 2014;5:24-34.

90. Patidar A, Thakur DS. Denderimer: potential carrier for drug delivery. Int J Pharm Sci Nanotech 2011;4:1383-9.

91. Priya P, Mand S, Jeyapragash R. Denderimer: a novel polymer. Int J Res Pharm Chem 2013;3:495-501.

92. Yiyun C, Zhenhua X, Minglu M, Tonguen X. Denderimers as drug carriers: applications in different routes of drug. J Pharm Sci 2008;97:123-43.

93. Vedha Hari BN, Kalaimangal K, Porkodi R, Gajula PK, Ajay JY. Denderimer: globular nanostructured material for drug delivery. Int J Pharm Tech Res 2012;4:432-51.

94. Agarwal Shweta, Murthy RSR, Kumar SL Hari, Garg Rajeev. Quality by design approach for development and characterisation of solid lipid nanoparticles of quetiapine fumarate. Curr Comput Aided Drug Des 2019;15. Doi:10.2174/1573409915666190722122827

95. Liggins RT, Burt HM. Polyether-polyester diblock copolymers for the preparation of paclitaxel loaded polymeric micelle formulations. Adv Drug Delivery Rev 2002;54:191-202.

96. Klumpp C, Kostarelos K, Prato M, Bianco A. Functionalized carbon nanotubes as emerging nanovectors for the delivery of therapeutics. Bio Biophys Act 2006;1758:404-12.

97. Talie MD, Wani AH, Ahmad N, Bhat MY, War JM. Green synthesis of silver nanoparticles (AgNPs) using helvella leucopus pers. and their antimycotic activity against fungi causing fungal rot of apple. Asian J Phama Clin Res 2020;13:161-5.

98. Singh Deepanmol, Pahwa Shilpa. A review on physic-chemical parameters of liposomal doxorubicin. Int J Appl Pharma 2020;12:1-5.

99. Vyas SP, Khar RK. Targeted and controlled drug delivery. CBS publication; 2008. p. 173-248.

100. R Shobha. Text book of industrial pharmacy. Orient longman private ltd. Publishers; 2019. p. 97-110.

101. Sapiun Z, Imran AK, Wicita PS, Kamba V, Slamet NS. Preparation and characterization of anchovy (stolephorus sp) protein concentrate nanoparticles using gelation method. Int J Appl Pharma 2019;12:109-11.

102. Kaur Nirlep, Yadav Kiran, Grag Rajeev, Saroha Kamal, Yadav Deepak. Formulation and in vitro characterization of ketoconazole span 80 based transfersomes gel, its comparison with liposomal gel and evaluation of antimicrobial activity. J Bionanosci 2016;10:1-14

103. Cevc G, Blume G. New, highly efficient formulation of diclofenac for the topical, transdermal administration in ultra-deformable drug carriers-transfersomes. Biochem Biophys Act 2001;1514:191-205.

104. Kaur N, Garg R, Devgan M, Singh A, Singh V. Ufasomes and transfersomes gel of oxiconazole: a comparative study. J Bionanosci 2017;11:194-202.

105. Verma P, Ram A, Jha AK, Mishra A, Thakur A. Phosphatidylcholine: a revolution in drug delivery technology. Int J Pharm Sci Res 2010;1:1-12.

106. Chien YW. Novel drug delivery systems. New York: Marcel Decker Inc; 1982. p. 149-215.

107. Nanda A, Nanda S, Dhall M, Rao R. Transferosomes-a novel ultra-deformable vesicular carrier for transdermal drug delivery. J Adv Pharm Tech Res 2005;5:395.

108. R Gref, A Domb, P Quellec, T Blunk, RH Mueller, JM Verbavatz, et al. The controlled intravenous delivery of drugs using PEGcoated sterically stabilized nanospheres. Adv Drug Delivery Syst 1995;16:215-33.

109. KS Soppimath, TM Aminabhavi, AR Kulkarni, WE Rudzinski. Biodegradable polymeric nanoparticles as drug delivery devices. J Controlled Release 2001;70:1-20.
110. T Ameller, V Marsaud, P Legrand, R Gref, G Barratt, JM Renoir. Polyester-poly (ethylene glycol) nanoparticles loaded with the pure antiestrogen: physicochemical and opsonization properties. J Pharm Res 2003;20:1063-70.

111. GS Kwon. Diblock copolymer nanoparticles for drug delivery. Crit Rev Ther Drug Carr Syst 1998;15:481-512.

112. Mu L, Feng SS. A novel controlled release formulation for the anticancer drug paclitaxel (Taxol囚): PLGA nanoparticles containing vitamin E TPGS. J Controlled Release 2003;80:33-48.

113. Zonghua L, Yanpeng J, Yifei W, Changren Z, Ziyong Z Polysaccharides-based nanoparticles as a drug delivery systems. Adv Drug Delivery Rev 2008;60:1650-62.

114. Jung TW, Kamm A, Breitenbach E, Kaiserling, Xiao JX, Kissel T. Biodegradable nanoparticles for oral delivery of peptides: is there a role for polymers to affect mucosal uptake. Eur J Pharm Biopharm 2000;50:147-60.

115. Illum L. Nanoparticulate systems for nasal delivery of drug: a real improvement over simple systems. J Pharm Sci 2007;86:473-83.

116. Raj Mohan VJ, Chen Y. Nanoparticles-a review. Trop J Pharm Res 2006;5:561-73.

117. M Antonietti, K Landfester. Polyreactions in miniemulsions. Prog Polym Sci 2002;27:689-757.

118. Asua JM. Miniemulsion polymerization. Prog Polym Sci 2002;27:1283-346.

119. P Couvreur, G Barratt, E Fattal, P legrand, C Vauthier. Nanocapsule technology: a review. Cri Rev Thera Drug Carr Syst 2002;19:99-134.

120. Muller RH, Mader K, Gohla S. Solid lipid nanoparticles for state of art. Eur J Pharm Biopharm 2000;50:161-77.

121. P Ekambaram, A Abdul Hasan Sathali, K Priyanka. Solid lipid nanoparticles: a review. Sci Rev Chem Comm 2012;2:80-102.

122. Agarwal Shweta, Kumar SL Hari, Garg Rajeev. Investigative study on impact of solid: liquid lipid ratio and stabilizer amount on some characteristics of nanostructure lipid carriers of quetiapine fumarate. Int J Pharma Invest 2019;2:47-52.

123. Houli Li, Xiaobin Zhao, Yukun Ma, Guangxi Zhai, Ling Bing Li, Hong Xiang Lou. Enhancement of gastrointestinal absorption of quercetin by solid lipid nanoparticles. J Controlled Release 2009;133:238-44.

124. Melike Uner, Gulgun Yener. Importance of solid lipid nanoparticles (SLN) in various administration routes and future perspectives. Int J Nanomed 2007;2:289-300.

125. Iqbal MA, Shadab Md, Sahni Jasjeet Kaur, Baboota S, Dang S, Ali J. Nanostructured lipid carriers system: recent advances in drug delivery. J Drug Targeting 2012;20:813-30.

126. A Pardakhty, E Moazeni. Nano-niosomesin drug, vaccine and gene delivery: a rapid overview. J Nanomed 2013;1:1-12.

127. S Verma, SK Singh, N Syan, P Mathur, V Valecha. Nanoparticle vesicular systems: a versatile tool for drug delivery. J Chem Pharm Res 2010;2:496-509.

128. Tarekegn A. Niosomes in targeted drug delivery: some recent advances. Int J Pharm Sci Res 2010;1:1-8.

129. M Carafa, E Santucci, G Lucania. Lidocaine-loaded non-ionic surfactant vesicles: characterization and in vitro permeation studies. Int J Pharm 2002;231:21-32.

130. M Ferrari. Cancer nanotechnology: opportunities and challenges. Nat Rev Can 2005;5:161-71.

131. PS Xu, EA Van Kirk, YH Zhan, WJ Murdoch, M Radosz, YQ Shen. Targeted charge-reversal nanoparticles for nuclear drug delivery. Ang Chemie Int 2007;46:4999-5002.

132. CM Paleos, D Tsiourvas, Z Sideratou, L Tziveleka. Acid and salttriggered multifunctional poly (propylene imine) dendrimer as a prospective drug delivery system. Biomacromolecules 2004;5:524-9.

133. ET Kisak, B Coldren, CA Evans, C Boyer, JA Zasadzinski. The vesosome-a multicompartment drug delivery vehicle. Curr Med Chem 2004;11:199-219.

134. W Wu, S Wieckowski, G Pastorin, M Benincasa, C Klumpp, JP Briand, et al. Targeted delivery of amphotericin B to cells by using functionalized carbon nanotubes. Ang Chem Int 2005;44:6358-62.

135. AK Salem, PC Searson, KW Leong. Multifunctional nanorods for gene delivery. Nat Mat 2003;2:668-71. 
136. Paciotti GF, Myer L, Weinreich D, Goia D, Pavel N, McLaughlin $\mathrm{RE}$, et al. Colloidal gold: a novel nanoparticle vector for tumor directed drug delivery. Drug Delivery 2004;11:169-83.

137. Paciotti GF, Kingston DGI, Tamarkin L. Colloidal gold nanoparticles: a novel nanoparticle platform for developing multifunctional tumor-targeted drug delivery vectors. Drug Delivery Res 2006;67:47-54.

138. Hong R, Han G, Fernandez JM, Kim BJ, Forbes NS, Rotello VM. Glutathione-mediated delivery and release using monolayer protected nanoparticle carriers. J Am Chem Soc 2006;128:1078-9.

139. Polizzi MA, Stasko NA, Schoenfisch MH. Water-soluble nitric oxide-releasing gold nanoparticles. Langmuir 2007;23:493843.

140. G Han, CC You, BJ Kim, RS Turingan, NS Forbes, CT Martin, et al. Light-regulated release of DNA and its delivery to nuclei by means of photolabile gold-nanoparticles. Angew Chem Int Ed 2006;45:3165-9.

141. Marchuk K. Guo Y, Sun W, Vela J, Fang N. High precision tracking with non blinking qunatum dots resolve nanoscale vertical displacement. J Am Chem Soc 2012;134:6108-11.

142. Dahan M. Diffusion dynamics of glycine receptors revealed by single-quantum dot tracking. Science 2003;302:442-5.

143. Oldenburg SJ, Averitt RD, Westcott SL, Halas NJ. Nanoengineering of optical resonances. Chem Phys Lett 1998;288:243-7.

144. Gobin Andre M, O'Neal D Patrick, Watkins Daniel M, Halas Naomi J, Drezek Rebekah A, West Jennifer L. Near infrared laser-tissue welding using nanoshells as an exogenous absorber. Lasers Surg Med 2005;37:123-9.

145. Hirsch LR, Jackson JB, Lee A, Halas NJ, West JL. A whole blood immunoassay using gold nanoshells. Anal Chem 2003;75:237781.

146. Valentin N Popov. Carbon nanotubes: properties and application. Mater Sci Eng 2004;43:61-102.

147. Kaur Rajwant, Vatta Pooja, Kaur Mandeep. Carbon nanotubes: a review article. Int J Res Appl Sci Eng Tech 2018;6:5075-9.

148. Kalpna Varshney. Carbon nanotubes: a review on synthesis, properties and applications. Int J Eng Res Gen Sci 2014;2:66077.

149. Jain NK. Pharmaceutical product development. $2^{\text {nd }}$ ed. CBS publishers; 2013. p. 216-7.

150. Leon Lachman, Herbert A Lieberman. The theory and practice of industrial pharmacy; 1986. p. 619-39.
151. Touitou E, Alkabes M, Dayan N, Eliaz. Ethosomes-novel vesicular carriers for enhanced delivery: characterization and skin penetration properties. J Controlled Release 2000;65:40318.

152. Jain S, Mishra D, A Kuksal, Tiwary AK. Vesicular approach for drug delivery into or across the skin: current status and future prospects. Int J Pharm 2006;69:251-8.

153. Kumar RT, Nitesh S, Chauhan Yogesh H. Ethosomes: potential carries for transdermal drug delivery. Int J Drug Delivery Res 2010;2:448-5

154. Chandel Abhishek, Patil Vishal, Goyal Rohit, Dhamija Hitesh, Parasha Bharat. Ethosomes: a novel approach towards transdermal drug delivery. Int J Pharm Chem Sci 2012;1:22775005.

155. Syeda SS, Sailaja K. Ethosomes: a novel approach in the design of transdermal drug delivery system. Int J Med Pharm Res 2016;2:17-22

156. Akiladevi, Sachinandan. Ethosomes a noninvasive approach for transdermal drug delivery. Int J Curr Pharm Res 2010;2:14.

157. Parmar Ramesh D, Parikh Rajesh K, Vidyasagar G, Patel Dhaval V, Patel Chirag, G Patel, Biraju D. Pulsatile drug delivery system: an overview. Int J Pharm Sci Nanotech 2009;2:227-34.

158. Sachin Survase, Neeraj Kumar. Pulsatile drug delivery: current scenario. CRIPS 2007;8:27-33.

159. Tomanek D. Modifying the bucky ball. Comp Mat Sci 1994;2:468-74.

160. D Lothar, Y Shangfeng. The recent state of endohedral fullerene research. Electrochem Soc Int Sum; 2006. p. 34-9.

161. Yamago S, Tokuyama H, Nakamura E, Kikuchi K, Kananishi S, Sueki $\mathrm{K}$, et al. In vivo behavior of a water-miscible fullerene: $14 \mathrm{C}$ labeling. absorption, distribution, exretion and acute toxicity. J Chem Biol 1995;2:385.

162. Ali khan A, Mudassir J, Mohtar N, Drawis X. Advance drug delivery to the lymphatic system: lipid-based nanoformulations. Int J Nanomed 2013;8:2733-44.

163. Cai S, Yang Q, Bagby TR, Forrest ML. Lymphatic drug delivery using engineered liposomes and solid lipid nanoparticles. Adv Drug Delivery Rev 2011;63(10 Suppl 11):901-8.

164. Winner B, Peipert JF, Zhao Q, Buckel C, Madden T, Allsworth JE, et al. Effectiveness of long-acting reversible contraception. $\mathrm{N}$ Eng J Med 2007;366:1998-2007.

165. Li Y, Zang SM, Chen F. A multi-center randomized controlled trial of intrauterine device used in chineses women. Zhonghua Yi Xue Za Zhi (Chinese) 2011;91:3172-5. 